\title{
Reliability assessments of corroded pipelines based on internal pressure - A review
}

\author{
Rafael Amaya-Gómez ${ }^{\mathrm{a}, \mathrm{c}, *}$, Mauricio Sánchez-Silva ${ }^{\mathrm{b}}$, Emilio Bastidas-Arteaga $^{\mathrm{c}}$, Franck Schoefs $^{\mathrm{c}}$, Felipe Muñoz $^{\mathrm{a}}$ \\ ${ }^{a}$ Chemical Engineering Department, Universidad de los Andes, Cra 1E No. 19A-40, Bogotá, Colombia \\ ${ }^{b}$ Department of Civil \& Environmental Engineering, Universidad de los Andes, Cra 1E No. 19A-40, Bogotá, Colombia \\ ${ }^{c}$ Université de Nantes, GeM, Institute for Research in Civil and Mechanical Engineering/Sea and Littoral Research Institute, CNRS UMR \\ 6183/FR 3473, Nantes, France
}

\begin{abstract}
Corrosion is one of the most significant threats for onshore pipelines that may lead to a Loss of Containment (LOC). A LOC poses significant consequences over the surrounding people and environment because of the hazardousness of the transporting fluids, so different efforts have been raised to predict pipe failures, which are commonly based on reliability assessments with limit state functions. These functions are gathered in serviceability, leakage, and ultimate conditions, out of which the last two approaches contemplate a LOC. This paper reviews recognized limit state functions for corroded pipelines, and it discusses their assumptions and applicability. Specifically, this paper focuses on burst limit pressures considering the relevance in the academic literature and Oil \& Gas standards. Therefore, a thorough comparison is presented based on failure criteria, acceptable defect dimensions, failure probability, and error prediction based on experimental and numerical burst tests. The objective is to evaluate the level of conservatism of each simplified model depending on the material toughness and the corrosion rate. This review aims to support a reliability model selection in corroded pipelines for future intervention strategies.
\end{abstract}

Keywords: Pipeline, Corrosion, Reliability, Plastic collapse.

\section{Introduction}

Structural reliability is commonly evaluated in terms of limit state functions (i.e., $g=R-D$ ), which define the distinction between failure and safe conditions given to a load/Demand $D$ and a resistance $R$ to fail $[1,2]$. If $g \leq 0$, the system is in a failure state, whereas if $g>0$, it is in a safe mode. In the case of pipelines, these functions are generally gathered into ultimate (ULS), leakage (LLS), and serviceability (SLS) pipe limit states depending if a Loss of Containment (LOC) occurs. According to the Canadian Standard Association (CSA), the ultimate condition refers to a LOC that represent a safety hazard; the leakage condition is also associated with a LOC, but limited to a $10 \mathrm{~mm}$ leak diameter; and finally, the serviceability condition is related to a deviation of the design or service requirements of the pipeline without producing any LOC [3].

From recognized limit functions, CSA Z662 [3] reported a thorough list of possible failures from internal or external conditions. Table 1 shows an extract of the CSA classification for LLS and ULS conditions considering timedependency and a stress/strain limit category. This table shows that internal pressure is one of the most relevant loads considered by decision-makers due to the possibility of a burst or leak. However, onshore pipelines are commonly located underground, so there are additional surface loads that affect the stress distribution, which can also induce a plastic collapse [4]. Finally, there are other loads like sabotage and surrounding conditions such as wind, slope instability, and outside forces that are complicated to predict, but still, some researchers focus their attention on these loads (see for instance $[5,6]$ ).

\footnotetext{
${ }^{*}$ Corresponding author,

Email address: r.amaya29@uniandes.edu.co (Rafael Amaya-Gómez)
} 
Table 1: Relevant limit state functions for onshore pipelines. Adapted from CSA Z662 [3].

\begin{tabular}{|c|c|c|c|c|c|}
\hline $\begin{array}{c}\text { Load } \\
\text { condition }\end{array}$ & Other loads & Limit state & $\begin{array}{l}\text { Failure } \\
\text { condition }\end{array}$ & $\begin{array}{l}\text { Stress/ } \\
\text { Strain } \\
\text { limit }\end{array}$ & $\begin{array}{c}\text { Time- } \\
\text { dependent }\end{array}$ \\
\hline \multirow{6}{*}{ Internal pressure } & \multirow{6}{*}{-} & -Burst at corrosion defect & ULS & Stress & Yes \\
\hline & & -Small leak at corrosion defect & LLS & Stress & Yes \\
\hline & & -Burst by SCC** & ULS & Stress & Yes \\
\hline & & -Small leak by SCC & LLS & Stress & Yes \\
\hline & & -Burst of manufacturing defect & ULS & Stress & Yes \\
\hline & & -Small leak of manufacturing defect & LLS & Stress & Yes \\
\hline \multirow[b]{2}{*}{$\begin{array}{l}\text { Overburden and } \\
\text { surface loads }\end{array}$} & \multirow[b]{2}{*}{ Internal pressure } & -Burst of a weld defect & ULS & Stress & Yes \\
\hline & & -Small leak of a weld defect & LLS & Stress & Yes \\
\hline $\begin{array}{l}\text { Aboveground } \\
\text { span settlement }\end{array}$ & $\begin{array}{l}\text { Internal pressure, } \\
\text { Gravity loads }\end{array}$ & Girth weld tensile fracture & ULS & Stress & Yes \\
\hline Wind* & $\begin{array}{c}\text { Internal pressure, } \\
\text { Gravity loads }\end{array}$ & Burst of crack by fatigue & ULS & Stress & Yes \\
\hline $\begin{array}{l}\text { Slope insta- } \\
\text { bility, ground } \\
\text { movement }\end{array}$ & $\begin{array}{l}\text { Internal pressure, } \\
\text { Seismic load, } \\
\text { Thermal expansion }\end{array}$ & Girth weld tensile fracture & ULS & Strain & Yes \\
\hline $\begin{array}{l}\text { Frost heave/ De- } \\
\text { frost settlement }\end{array}$ & $\begin{array}{l}\text { Internal pressure, } \\
\text { Seismic load, } \\
\text { Thermal expansion }\end{array}$ & Girth weld tensile fracture & ULS & Strain & Yes \\
\hline $\begin{array}{l}\text { River bottom ero- } \\
\text { sion }\end{array}$ & $\begin{array}{c}\text { Internal pressure, } \\
\text { Thermal expansion, } \\
\text { Buoyancy }\end{array}$ & Girth weld tensile fracture & ULS & Strain & No \\
\hline \multirow{2}{*}{ Outside force } & \multirow{2}{*}{ Internal pressure } & -Puncture & ULS & Stress & No \\
\hline & & -Burst of a gouged dent & ULS & Stress & No \\
\hline Sabotage & Internal pressure & Puncture & ULS/LLS & Stress & No \\
\hline
\end{tabular}

These limit functions are relevant because they support decisions about future interventions upon an acceptable level of reliability or risk; however, economic losses can be obtained depending on their level of conservatism. In one hand, if the pipeline is not intervened because the limit condition is exaggerated and a LOC takes place, people and the environment in the surroundings can be affected due to the hazardousness of the transporting fluids (i.e., flammable, explosive, toxic). For instance, the Pipeline and Hazardous Materials Safety Administration (PHMSA) in the USA reported 1696 accidents of gas and hazardous Liquids from 2010 to 2018. These accidents produced 59 fatalities, 357 injuries, and costs higher than USD 518 million including property damage, commodity loss, emergency response, and environmental remediation [7]. On the other hand, if failure distinction is extremely conservative, unnecessary interventions (i.e., maintenance or replacements) can be implemented representing direct economic losses for pipe owners. In either case, to prevent extreme economic losses, decision-makers have to evaluate the reliability of the pipeline as-good-as-possible by considering the current condition of the pipe [8,9], thus, updating the failure resistance based on information from inspection results like In-Line Inspections (ILI).

ILI inspections commonly report metal loss at the inner and outer wall of the pipelines concerning corrosion defects, cracks, gouges, and dents. These flaws reduce pipes resistance to withstand their intended operation and surrounding loads, which make pipelines more prone to fail by plastic deformation, leak or burst depending on the wall thickness consumption and the material strength. A failure in the material can be described in terms of different strength theories based on principal stresses. For instance, the maximum principal stress theory states that a failure occurs when these stresses are greater than critical tensile or compressive strengths, which can be associated with the steel yield or ultimate stresses to evaluate a yield failure or a plastic collapse. Considering that corrosion defects is one of the most frequent causes of failure of hydrocarbon pipelines, this review will focus on available approaches to evaluate the reliability of corroded pipelines regarding plastic deformation or plastic collapse.

Plastic deformation is associated with non-recoverable deformations once the yield strength $\sigma_{y}$ is exceeded from the corresponding equivalent stress $\sigma_{\text {Equiv }}$, which can be determined following the Von Mises or Tresca criteria. Some of the available approaches like the reported by Ahammed \& Melchers [10] and Amirat et al. [11] present a nonlinear limit state model for the analysis of underground pipelines, both in circumferential and longitudinal directions. A 
plastic collapse failure is associated with the impossibility of the remaining wall thickness to withstand the ultimate strength [12]. Hence, this failure is related to the occurrence of a burst due to the operating pressure of the pipe as in the following limit state function: $g_{P}=P_{b}-P$. Here $P_{b}$ is the burst pressure in which the pipe wall will bulge outward and reach a point of instability [13], and $P$ is the pipeline operating pressure. Some of the available models for this criterion are implemented in standards such as ASME B31G [14], DNV RPF-101 [15], CSA Z662-07 [3], and the model reported by Netto et al. [16].

The objective of this paper is to review available approaches for evaluating a burst of corroded pipelines considering their relevance in maintenance and risk assessment decisions. However, additional approaches to describe plastic deformation are also discussed. In comparison to other relevant reviews [17-23], this paper aims to evaluate the main available approaches concerning their level of conservatism subjected to the assumptions of each model; therefore, the models will be described in detail with a homogeneous nomenclature. The document is structured as follows: Section 2 describes an interesting yield criterion based on the longitudinal and circumferential stresses and the Von Mises criterion. Section 3 presents available approaches to estimate the burst pressure of a corroded pipeline including their limitations and assumptions. Section 4 compares the main approaches regarding their failure criterion, failure probability, and prediction error. Finally, some concluding remarks are given in Section 5.

\section{Yield criterion and application for corroded pipelines}

Underground pipelines are subject to tension and compression stresses from the surrounding soil and their internal pressure, which make the hoop stress to be the maximum principal stress and the radial stress to be negligible. For a yield failure and a posterior plastic collapse evaluation, different criteria like the Tresca (Maximum Shear Stress Theory), Von Mises (Maximum Distortion Energy), or ASSY (Average Shear Stress Yield) are commonly implemented for corroded pipelines [24, 25].

Particularly for plastic deformation, Ahammed \& Melchers [26] developed two approaches that evaluate the reliability of corroded pipelines based on uniform corrosion as degradation process. Initially, they assumed that the longitudinal loads are unchanged along the pipeline and the pipeline is not subjected to temperature changes, whereas the cross-section is in plane strain state. Other additional assumptions include: the internal pressure produces homogeneous tension circumferentially and the hoop stress produced by the operating pressure of the fluid is algebraically additive to the circumferential stresses from external forces [26].

Following the aforementioned assumptions, Ahammed \& Melchers [26] considered the following expressions for the hoop stress due to the internal fluid pressure $\sigma_{P c}$ and the bending stresses (external loads $\sigma_{S c}$ and traffic loads $\sigma_{T c}$ ) based on the results of Spangler \& Handy [27]:

$$
\begin{aligned}
\sigma_{P c} & =\frac{P r}{t}, \\
\sigma_{S c} & =\frac{6 k_{m} C_{d} \gamma B_{d}^{2} E t r}{E t^{3}+24 k_{d} P r^{3}}, \\
\sigma_{T c} & =\frac{6 k_{m} I_{c} C_{t} F E t r}{L_{e}\left(E t^{3}+24 k_{d} P r^{3}\right)},
\end{aligned}
$$

where $P$ is the internal pressure, $r$ is the internal radius, $t$ is the wall thickness, $k_{m}$ is the bending coefficient, $C_{d}$ is the coefficient of earth pressure, $\gamma$ is the unit weight of the soil, $B_{d}$ is the width of the ditch, $E$ is the elasticity modulus, $k_{d}$ deflection coefficient, $I_{c}$ is the impact factor, $C_{t}$ is the surface load coefficient, $F$ is the surface wheel load, and $L_{e}$ is the effective pipe length.

The authors then extended the first approach version by considering stresses in the longitudinal direction [10]. The stresses address the effect of the fluid pressure $\sigma_{P l}$ (tensile stress), the thermal expansion along the pipeline $\sigma_{S l}$, and a maximum longitudinal bending stress $\sigma_{T l}$ :

$$
\begin{aligned}
\sigma_{P l} & =\frac{\mu P r}{t}, \\
\sigma_{S l} & =\alpha E \Delta \theta, \\
\sigma_{T l} & =E r \chi,
\end{aligned}
$$


where $\mu$ is the Poisson's ratio, $\alpha$ is the thermal expansion coefficient, $\Delta \theta$ is the temperature variation, and $\chi$ is the longitudinal curvature. For this approach, Ahammed \& Melchers [10] considered a failure criterion associated with a loss of structural strength by implementing the distortion energy criterion because of acceptable results for ductile materials. The limit state function $g_{S}$ can be expressed in terms of longitudinal and circumferential stresses as follows:

$$
g_{S}=\sigma_{y}-\sigma_{E q u i v}=\sigma_{y}-\sqrt{\sigma_{c}^{2}-\sigma_{c} \sigma_{l}+\sigma_{l}^{2}}
$$

The circumferential $\sigma_{c}$ and longitudinal $\sigma_{l}$ stresses are given by:

$$
\begin{aligned}
& \sigma_{c}=\sigma_{P c}+\sigma_{S c}+\sigma_{T c}, \\
& \sigma_{l}=\sigma_{P l}+\sigma_{S l}+\sigma_{T l} .
\end{aligned}
$$

A final extension of this approach was proposed by Amirat et al. [11] by incorporating residual stresses. These stresses are commonly found inside materials due to construction, thermal, and mechanical/heat formation processes, but in the case of pipelines, residual stresses are generated in hot lamination processes, which introduce a significant deformation [28]. The approach of Amirat et al. is based on the Crampton's model, which determines residual circumferential stresses $\sigma_{\text {Resc }}$ for thin pipelines cutting on the complete system with the aim of measuring their diameter changes. This result in a relaxation of the stresses in corroded pipelines due to a redistribution throughout the pipeline remaining wall thickness. Then, the Crampton equation for corroded pipelines can be expressed in terms of the corroded layer $t_{c}$, the radial coordinate $r_{t}$, and $t$ as follows [11]:

$$
\sigma_{\text {Resc }}=-70\left(1-\frac{2 t_{c}}{t}\right)\left(1-\frac{2\left(r_{t}-t_{c}\right)}{t-t_{c}}\right) .
$$

The longitudinal residual stress is determined with the Poisson coefficient $\mu$ and the circumferential stress $\sigma_{\text {Resc }}$ by $\sigma_{\text {Resl }}=\mu \sigma_{\text {Resc }}$. Both residual stresses would be added to the ones reported in Eq. 8. This approach was shown to be relevant for the failure probability calculation, the time between inspections selection, and the associated costs optimization [29, 30]. Indeed, the influence of residual stresses have been shown to be important for 20 years of evaluation, and then it becomes less sensitive to failure probability calculations [29].

Besides these approaches, there are some interesting pieces of work focusing on cast iron pipelines, which could be applicable under some assumptions [31-33]. For instance, Ji et al. [31] evaluate large-diameter cast iron pipelines based on finite element simulations following probabilistic modeling. For this purpose, the authors used a limit state function with the yield strength and time-dependent working stress that depends on the pipeline location, backfill soil, physical pipe properties, and surrounding loads.

\section{Burst pressure}

\subsection{Internal pressure}

Consider a pipeline of one unit length operating at an internal pressure $P$, a diameter $D$, and wall thickness $t$, which is subject to an external pressure $P_{o}$. The free diagram of the circumferential direction of this pipeline is depicted in Fig. 1a. In case the external pressure is omitted and only the vertical direction is contemplated, then Fig. 1b shows the correspondent free diagram. Based on a vertical equilibrium and the mean hoop or tangential stress $\sigma_{h}$, the internal pressure can be estimated with the Barlow's equation [34].

$$
P=\frac{2 \sigma_{h} t}{D}
$$

The Barlow formula estimates the internal pressure that a pipe can withstand given its geometry $(t / D)$ and material strength $\left(\sigma_{h}\right)$. The hoop stress can be replaced by the yield $\left(\sigma_{y}\right)$ or ultimate strengths $\left(\sigma_{u}\right)$ multiplied by a safety factor $F$, which changes depending on the approach [20]. 

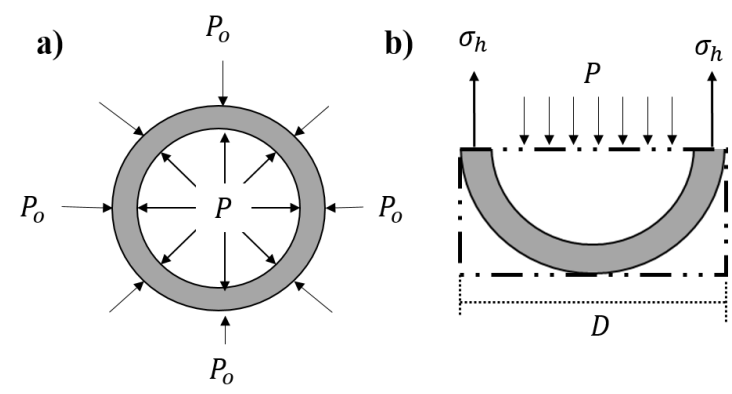

Figure 1: Free Diagram pressurized pipeline. Adapted from [34].

\subsection{Burst pressure for intact pipelines}

Some available approaches estimate the burst pressure for free-defect pipes or with grooves with an infinite longitude. These approaches consider yield failure criteria following the Von Mises, Tresca or ASSY (Average Shear Stress Yield) criteria [24, 35]. The burst pressure for these three criteria can be expressed as follows:

$$
P_{b}=\left(\frac{k}{2}\right)^{n+1} \frac{4 t}{D} \sigma_{u},
$$

where $n$ the strain hardening exponent and $k$ is a constant that depends on the implemented yield criterion as follows [36]:

$$
k= \begin{cases}1 & , \text { Tresca } \\ 2 / \sqrt{3} & , \text { Von Mises } \\ 1 / 2+1 / \sqrt{3} & , \text { ASSY. }\end{cases}
$$

From these criteria, Zhu \& Leis [24] developed a comparison with 103 full-size burst tests of Grade B to X65 obtaining that the Tresca and Von Mises criteria corresponded with the lower and upper bounds, whereas the ASSY approach described the plastic collapse closely. Maes et al. [35] considered the combined effect of burst pressure with tension or bending. Law \& Bowie [37] and Zhu \& Leis [25] reported other models that can predict the burst pressure of intact pipelines. From these models, it is highlighted the use of the Barlow equation with the ultimate strength as hoop stress, and the approaches from Fletcher, Maximum Shear Stress, Turner, ASME boiler code, and Bailey-Nadai. These highlighted approaches are presented in Table 2, where $\epsilon_{u}$ is the uniform strain, $\sigma_{\text {flow }}$ is the flow stress, $D_{i}$ is the internal diameter, and $\hat{k}=r / r_{i}$. Where $r_{i}$ is the inner radius. For a complete comparison with burst tests, the reader is referred to $[25,37]$.

Table 2: Acceptable burst pressure model for intact pipelines. Adapted from [37].

\begin{tabular}{ll}
\hline Model & Equation \\
\hline ASME Boiler code & $P=\sigma_{u}\left(\frac{\hat{k}-1}{0.6 \hat{k}+0.4}\right)$ \\
Bailey-Nadai & $P=\frac{\sigma_{u}}{2 n}\left(1-\frac{1}{\hat{k}^{2 n}}\right)$ \\
Fletcher & $P=\frac{2 t \sigma_{\text {flow }}}{D_{i}\left(1-\epsilon_{u} / 2\right)}$ \\
Max Shear Stress & $P=2 \sigma_{u}\left(\frac{\hat{k}-1}{\hat{k}+1}\right)$ \\
Turner & $P=\sigma_{u} \ln (\hat{k})$ \\
\hline
\end{tabular}

\subsection{Failure overview for a corroded pipeline}

For a pipeline with a corrosion defect with a depth $d$ and a length $l$, the hoop stress is replaced by a flow stress $\sigma_{\text {flow }}$ and a term that represents the strength reduction of the pipeline due to the growth of the corrosion area. The equation was denominated as NG-18 [38, 39]: 


$$
\sigma_{h f}=\sigma_{\text {flow }}\left[\frac{1-A_{c} / A_{o}}{1-\left(A_{c} / A_{o}\right) M^{-1}}\right],
$$

where $M$ is known as the Folias or bulging factor, which is a geometry correction factor that associates a stress distribution from a crack plate with a cylindrical vessel in terms of the so-called degree of the corrosion extent [40, 41]. $A_{o}$ is the intact longitudinal area before the corrosion defect takes place (i.e., $A_{o}=t l$ ), and $A_{c}$ is the corroded area, which is a function of the defect depth and length. These areas correspond to metal loss projections in the longitudinal plane based on the wall thickness [42]. In this direction, different defect shapes such as parabolic $((2 / 3) d l)$, rectangular $(d l)$, or mixed $(0.85 d l)$ approaches have been proposed (Fig. 2). The latter corresponds to a shape obtained by combining the $45 \%$ of the depth of the parabolic approach and the 55\% of a rectangular approach, i.e., $0.85 d l=(0.55) d l+(0.45)(2 / 3) d l$.

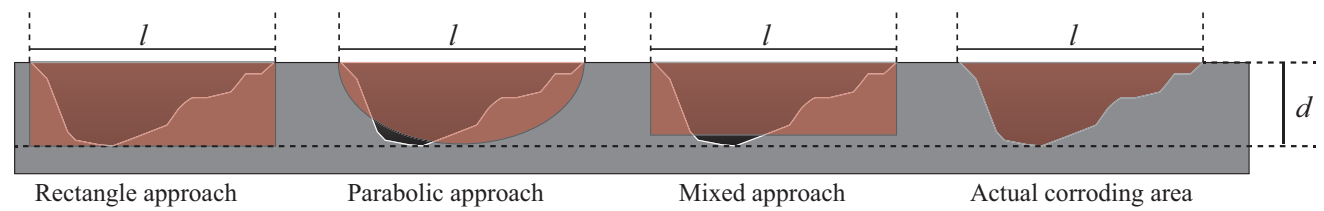

Figure 2: Rectangle, Parabolic, Mixed, and Effective corroding area comparison.

According to Mustaffa [43], the NG-18 equation assumes that a failure occurs because of a stress-dependent mechanism; therefore, the flow stress is described based on the yield or the ultimate tensile strengths, as in the case of an intact pipeline. Some of the available methods following NG-18 equations are depicted in Table 3, where it can be noted that the flow stress lies between the yield and ultimate strengths.

Table 3: Methods for assessing burst strength following the NG-18 equation. Adapted from [44].

\begin{tabular}{llll}
\hline \multicolumn{1}{c}{ Method } & $\begin{array}{c}\text { Flow } \\
\text { stress* }\end{array}$ & \multicolumn{1}{c}{$\begin{array}{c}\text { Defect } \\
\text { shape }\end{array}$} & \multicolumn{1}{c}{ Folias Factor } \\
\hline NG-18 & $\sigma_{y}+69$ & $\begin{array}{l}\text { Rectangular/ } \\
\text { defect area }\end{array}$ & $\sqrt{1+0.6275\left(\frac{l^{2}}{D t}\right)-0.003375\left(\frac{l^{2}}{D t}\right)^{2}}$ \\
ASME & $1.1 \sigma_{y}$ & Parabolic & $\sqrt{1+0.8\left(\frac{l^{2}}{D t}\right)}$ \\
B31G & $\sigma_{y}+69$ & Mixed & $\sqrt{1+0.6275\left(\frac{l^{2}}{D t}\right)-0.003375\left(\frac{l^{2}}{D t}\right)^{2}}$ \\
Modified & Effective & $\sqrt{1+0.6275\left(\frac{l^{2}}{D t}\right)-0.003375\left(\frac{l^{2}}{D t}\right)^{2}}$ \\
B31G & $\sigma_{y}+69$ & $\begin{array}{l}\text { area/length } \\
\text { RSTRENG }\end{array}$ & $\sqrt{1+0.8\left(\frac{l^{2}}{D t}\right)}$ \\
SHELL92 & $\sigma_{u}$ & Rectangular & $\sqrt{\left.1+\frac{l^{2}}{D t}\right)}$ \\
DNV & $\sigma_{u}$ & Rectangular & $\sqrt{1+0.31(1+2)}$ \\
RP-F101 & & &
\end{tabular}

In this table, there are two relevant classifications of the flow stress and the defect shape. A flow stress of $1.1 \sigma_{y}$ is suggested for a carbon steel pipeline which operates at a temperature below $120^{\circ} \mathrm{C}$; and a flow stress of $\sigma_{y}+69[\mathrm{MPa}]$ could be used for carbon and low alloy steel pipelines which have a yield strength lower than $483 \mathrm{MPa}$ (70ksi) and operates under $120^{\circ} \mathrm{C}$ [14]. Other approaches depend on the operating pressure following the ASME Boiler and Pressure Code or using a linear interpolation between the yield and the ultimate strengths. Regarding the defect shape, they are idealized as rectangular, parabolic, mixed areas, or as in the case of RSTRENG takes the complete profile of the defect. Figure 2 shows a scheme of the ASME B31G, ModB31G, and RSTRENG approaches, which follow a decreasing level of conservatism because of the defect shape idealization and the ratio between flow stress ratio and ultimate strength. According to Benjamin et al. [42], predictions are more conservative for lower ratios.

Since the definition of the limit state function requires estimating the resistance/capacity pressures (i.e., $P_{b}$ ), some of the more relevant approaches available in the literature will be presented in the following section. These approaches consider information that can be obtained from In-Line (ILI) inspections such as $D, t, l, d, \sigma_{y}$, and $\sigma_{u}$. Consequently, 
their outcomes are useful for optimizing risk-based life-cycle assessments and maintenance optimization for the implementation from pipeline operators and decision-makers.

\subsection{ASME B31G and modifications}

ASME has a supplement to ASME B31 (Code for pressure piping) that is associated with the manual to determine the remaining strength of corroded pipelines. This manual includes three levels of assessment out of which two of them are of interest in this work. Level 1 provides a simple estimation of the remaining strength with the maximum extent of the metal loss (depth and length), whereas Level 2 implements a detailed surface profile of the defect. As it was mentioned above, the burst pressure criteria reported by ASME follows the NG-18 equation (see Table 3), and it is one of the conventional approaches used by the Oil \& Gas industry [45].

The first burst pressure developed in 1984 considers a parabolic estimate of the metal loss shape and a distinction between short defects (i.e., $\left.l^{2} / D t \leq 20\right)$ and long defects $\left(l^{2} / D t>20\right)$, which are assumed to behave like infinitively long defects. Based on the Folias factor shown in Table 3, the burst pressure can be computed as [14]:

$$
P_{b}= \begin{cases}\frac{2 t}{D}\left(1.1 \sigma_{y}\right)\left[\frac{1-(2 / 3)(d / t)}{1-(2 / 3)(d / t) M^{-1}}\right] & , l^{2} / D t \leq 20 \\ \frac{2 t}{D}\left(1.1 \sigma_{y}\right)[1-(d / t)] & , l^{2} / D t>20 .\end{cases}
$$

This criterion was modified in 1991, changing the way the shape of the metal loss and stress flow are evaluated. The Mixed approach was used for the corroding area, which is a less pessimistic assumption in comparison to the parabolic shape; and the stress flow for a carbon/alloy steel was considered instead. This modified version is given by:

$$
P_{b}=\frac{2 t}{D}\left(\sigma_{y}+69[M P a]\right)\left[\frac{1-0.85(d / t)}{1-0.85(d / t) M^{-1}}\right],
$$

where the Folias factor was replaced for less conservative results based on the geometry of the pipeline as follows:

$$
M= \begin{cases}\sqrt{1+0.6275\left(\frac{l^{2}}{D t}\right)-0.003375\left(\frac{l^{2}}{D t}\right)^{2}} & , l^{2} / D t \leq 50 \\ 3.3+0.032\left(\frac{l^{2}}{D t}\right) & , l^{2} / D t>50 .\end{cases}
$$

In 2009, ASME developed the last modification of this criterion using what is known as the Effective Area Method. This method, which is also called RSTRENG or Level 2 assessment, implements the actual area of the metal loss that can be arranged in a grid pattern in an iterative process to estimate the lowest failure stress [14]. This criterion is given by:

$$
P_{b}=\frac{2 t}{D} \sigma_{\text {flow }}\left[\frac{1-A / A_{o}}{1-\left(A / A_{o}\right) M^{-1}}\right],
$$

where the ratio $A / A_{o}$ is the percentage of lost material.

These approaches are routinely used by operators because of their level of conservatism. For instance, Abdalla Filho et.al [46] suggest that the ASME B31G and Modified B31G criteria are suitable for short corrosion defects because the difference with reference burst pressures obtained with FEM lies within 10 to $18 \%$. In fact, software such as KAPA (Kiefner and Associates Pipe Assessment) have been proposed for this purpose with the aim to follow ASME B31.4, B31.8, and in accordance with 49 CFR Part 192 \& 195 [47]. However, the level of conservatism could be unsatisfactory for long corrosion defects for the case of the Modified B31G criterion by obtaining differences from 25 to $40 \%$ [46], which can be attributed to the defect geometric shape (i.e., half depth rectangle and parabola) [48]. To deal with this problem, Benjamin \& Andrade [49] proposed a method known as Rectangular Parabolic Area (RPA) to provide a higher level of conservatism for long corrosion defects with the following burst pressure [50]:

$$
P_{b}=\frac{2 t}{D}\left(\sigma_{y}+69 M P a\right)\left[\frac{1-a(d / t)}{1-a(d / t) M^{-1}}\right],
$$




$$
M= \begin{cases}\sqrt{1+0.6275\left(\frac{l^{2}}{D t}\right)-0.003375\left(\frac{l^{2}}{D t}\right)^{2}} & , l^{2} / D t \leq 20 \\ 2.1+0.7\left(\frac{l^{2}}{D t}\right) & , l^{2} / D t>20,\end{cases}
$$

where $a=0.85$ for $l^{2} / D t \leq 20$ and $a=1-0.15\left(64 \times 10^{6}\right) /\left(l^{2} / D t\right)^{6}$ otherwise. This method uses the same burst predictions for short defects (i.e., $l^{2} / D t<20$ ), but assumes that the defects follow a longitudinal shape obtained from a rectangle with a parabola (see Fig. 3) and that the Folias Factor can be extrapolated from the expression of ASME [48].

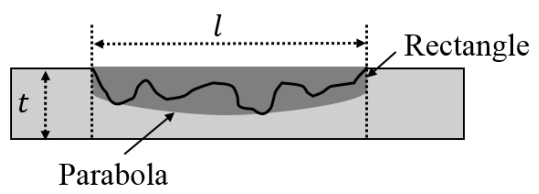

Figure 3: RPA geometric defect shape. Adapted from [48].

Despite that Oil \& Gas operators commonly use these approaches, there are some limitations in their implementation. For instance, the range of application of these methods is within defect-depths from 10 to $80 \%$ of the pipe wall thickness. Based on FEM comparisons with the maximum allowable pressure, the Modified ASME B31G may not be conservative for long and deep defects, but for shallow corrosion defects [51]. In addition, some flaws are outside of the scope of these approaches such as cracks, gouges, weld or seam corrosion [14].

\subsection{Approaches proposed by Choi et al. [51] and Chen et al. [52]}

Based on a series of elastic-plastic FEM simulations, Choi et al. [51] proposed a limit state evaluation for X65 corroded pipelines following elliptical defects. This approach was proposed based on 7 burst tests from a transmission pipeline of KOGAS and 30 FEM simulations changing the ratios $R / t$ (thinner pipelines), $d / t$ (remaining wall thickness), $l / \sqrt{r t}$ (extent of corrosion defect), and by fixing the width $w$ of the synthetic defects to $\pi R / 10$, which represents the $10 \%$ of half circumference as is illustrated in Fig. 4. This model considers a failure when the Von Mises stress rises to $0.8 \sigma_{u}$.

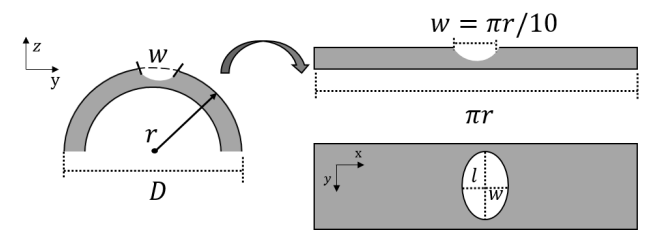

Figure 4: Defects idealization of the Choi et a.1 [51] model.

Considering regression analysis from the obtained FEM and burst test results, they obtained the following expression:

$$
P_{b}= \begin{cases}\frac{2 t}{D}\left(0.9 \sigma_{u}\right)\left[C_{0}+C_{1}\left(\frac{l}{\sqrt{r t}}\right)+C_{2}\left(\frac{l}{\sqrt{r t}}\right)^{2}\right] & , \text { for } l / \sqrt{r t}<6 \\ \frac{2 t}{D} \sigma_{u}\left[C_{3}+C_{4}\left(\frac{l}{\sqrt{r t}}\right)\right] & , \text { for } l / \sqrt{r t} \geq 6,\end{cases}
$$

where: $C_{0}=0.06\left(\frac{d}{t}\right)^{2}-0.1035\left(\frac{d}{t}\right)+1 ; C_{1}=-0.6913\left(\frac{d}{t}\right)^{2}+0.4548\left(\frac{d}{t}\right)-0.1447 ; C_{2}=0.1163\left(\frac{d}{t}\right)^{2}-0.1035\left(\frac{d}{t}\right)+$ $0.0292 ; C_{3}=-0.9847\left(\frac{d}{t}\right)+1.1101 ; C_{4}=0.0071\left(\frac{d}{t}\right)-0.0126$.

A similar approach was proposed by Chen et al. [52] for X80 and X90 pipelines with single corrosion defects. For this purpose, they used nonlinear regression from Finite Element simulations using different defects configurations.

$$
P_{b}=\frac{2 t \sigma_{u}}{D-t} C
$$


where $C$ is the result of regression analyses based on the structure proposed by Choi et al. [51].

$$
C= \begin{cases}{\left[c_{0}\left(\frac{l}{\sqrt{D t}}\right)^{2}+c_{1}\left(\frac{l}{\sqrt{D t}}\right)+c_{2}\right]\left[c_{3}\left(\frac{w}{\pi D}\right)^{2}+c_{4}\left(\frac{w}{\pi D}\right)+c_{5}\right]} & , \text { for } l / \sqrt{D t} \leq 5, w / \pi D \leq 0.3 \\ {\left[c_{6}\left(\frac{l}{\sqrt{D t}}\right)+c_{7}\right]\left[c_{3}\left(\frac{w}{\pi D}\right)^{2}+c_{4}\left(\frac{w}{\pi D}\right)+c_{5}\right]} & , \text { for } l / \sqrt{D t}>5, w / \pi D \leq 0.3 \\ {\left[c_{8}\left(\frac{l}{\sqrt{D t}}\right)^{2}+c_{9}\left(\frac{l}{\sqrt{D t}}\right)+c_{10}\right]} & , \text { for } l / \sqrt{D t} \leq 5, w / \pi D>0.3 \\ {\left[c_{11}\left(\frac{l}{\sqrt{D t}}\right)+c_{12}\right]} & , \text { for } l / \sqrt{D t}>5, w / \pi D>0.3\end{cases}
$$

where: $c_{0}=0.000194+0.0135\left(\frac{d}{t}\right)+0.0221\left(\frac{d}{t}\right)^{2} ; c_{1}=0.00482-0.202\left(\frac{d}{t}\right)-0.169\left(\frac{d}{t}\right)^{2} ; c_{2}=1.0604-0.253\left(\frac{d}{t}\right)+$ $0.194\left(\frac{d}{t}\right)^{2} ; c_{3}=-4.016+13.195\left(\frac{d}{t}\right) ; c_{4}=1.583-5.337\left(\frac{d}{t}\right) ; c_{5}=0.975+0.00872\left(\frac{d}{t}\right) ; c_{6}=0.000238-0.0105\left(\frac{d}{t}\right) ;$ $c_{7}=1.108-0.974\left(\frac{d}{t}\right) ; c_{8}=-0.00239+0.0308\left(\frac{d}{t}\right)-0.00382\left(\frac{d}{t}\right)^{2} ; c_{9}=0.0314-0.381\left(\frac{d}{t}\right)+0.101\left(\frac{d}{t}\right)^{2} ; c_{10}=$ $0.993+0.185\left(\frac{d}{t}\right)-0.579\left(\frac{d}{t}\right)^{2} ; c_{11}=-0.000586-0.00771\left(\frac{d}{t}\right) ; c_{12}=1.129-1.0808\left(\frac{d}{t}\right)$.

\subsection{Corroded Pipe Strength (CPS)}

Cronin \& Pick proposed a model for predicting corrosion failure pressure based on a method named as Corroded Pipe Strength (CPS) [53]. This method considers a detailed profile of a corrosion defect based on a Weighted Depth Difference Method, which uses interpolation between the burst pressures obtained from a plain pipe $P_{p p}$ (upper limit) and a pipe with an axially oriented long groove $P_{L G}$ (lower limit). For this interpolation, a geometric factor $g^{f}$ is implemented once the profile of the defect is assumed to be rectangular as follows[53]:

$$
P_{b}=P_{L G}+g^{f}\left(P_{p p}-P_{L G}\right) .
$$

The burst pressure from a plain pipe was determined using the instability pressure reported by Svennson [54] with the Ramberg-Osgood material model, which estimates the true strain $\epsilon_{T}$ and stress $\sigma_{T}$ of the pipeline. Once elastic strains were neglected and a regression analysis was performed with experimental results, the following expression was obtained [53]:

$$
P_{p p}=0.9\left(\frac{E \sigma_{y}^{n_{R}-1}}{\sqrt{3} \alpha_{R} n_{R}}\right)^{1 / n_{R}} \frac{2 t}{\sqrt{3} r_{i}\left[\exp \left(2 n_{R}\right)^{-1}\right]^{2}},
$$

where $n_{R}$ and $\alpha_{R}$ are parameters characterized by Ramberg-Osgood, and $r_{i}$ is the inner radius (i.e., $r_{i}=D / 2-t$ ). From these parameters, the Ramberg exponent $n_{R}$ can be determined based on the yield or ultimate pipe strengths by estimating the reciprocal of the Hollomon strain exponent $[55,56]$; whereas $\alpha_{R}$ can be obtained setting a yield offset, for instance, of $0.2 \%$ as follows [57]:

$$
\alpha_{R} \frac{\sigma_{Y}}{E}=0.002 .
$$

For the burst pressure of the long groove, Cronin \& Pick [53] assumed that the material is incompressible and they neglected plain pipe deformation and bulging defects. Considering defects with a depth greater than $0.2 t$, they obtained the following equation[53].

$$
P_{L G}=\frac{2 \sigma_{c r i t}}{(D-2 t) \sqrt{3 / 4}}(t-d) \exp \left(-\sqrt{3 / 4} \epsilon_{c r i t}\right),
$$

where $\sigma_{c r i t}$ and $\epsilon_{c r i t}$ are the critical stress and strain of the pipeline, which are estimated from the ultimate stress $\left(\sigma_{u}\right)$ and the uniform strain at this stress $\left(\epsilon_{u}\right)$ given as follow: $\sigma_{c r i t}=\sigma_{u}\left(1+\epsilon_{u}\right)$ and $\epsilon_{c r i t}=\ln \left(1+\epsilon_{u}\right)$ [53].

Finally, to consider the actual corrosion geometry, Cronin \& Pick [53] used a hyperbolic secant function in the weighted depth process with a normalized distance in the longitudinal direction (i.e., $l / \sqrt{D(t-d)}$ ) and the depth difference with an evaluation location. This approach assumes a limited corroded width and several measurements uniformly separated, which are latter approximated with step shapes as depicted in Fig. 5. 


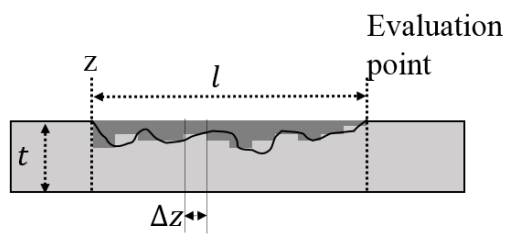

Figure 5: CPS defect profile approximation. Adapted from [53].

The geometry factor is defined by an iterative process based on the defect profile measurements, which includes the contribution of all the weighted depth distances from each step and the maximum from these measurement points. Despite that this approach has a simplified version shown below [17, 19], it is not suitable for practical purposes.

$$
g^{f}=\frac{4 \tan ^{-1}[\exp \{-l /(2 \sqrt{D(t-d)})\}]}{\pi} .
$$

\subsection{CSA Z662-07}

The CSA pressure criterion (also called as C-FER model [58]) describes the pressure necessary to reach a plastic collapse on a corroded surface for high grade steels $\left(\sigma_{y}>241 \mathrm{MPa}\right)$ and low grade steels $\left(\sigma_{y} \leq 241 \mathrm{MPa}\right)$. This approach was calibrated using burst tests obtaining model errors factors as follows:

$$
P_{b}= \begin{cases}e_{1} P_{b i}+\left(1-e_{1}\right) P-e_{2} \sigma_{u} & , \sigma_{y}>241 M P a \\ e_{3} P_{b i}+\left(1-e_{3}\right) P-e_{4} \sigma_{y} & , \sigma_{y} \leq 241 M P a,\end{cases}
$$

where, $e_{1}, e_{2}, e_{3}$, and $e_{4}$ describe model errors, $P_{b i}$ is the calculated pressure strength, and $P$ is the pressure strength from a perfect pipeline. These errors were estimated based on the actual resistance from burst tests using linear fitting with the calculated strength [58]. The reported errors are $e_{1}=1.04, e_{2}=\mathcal{N}\left(-0.00056,0.001469^{2}\right), e_{3}=1.17$, and $e_{4}=\mathcal{N}\left(-0.007655,0.006506^{2}\right)$ [3]. Where $\mathcal{N}\left(\mu, \sigma^{2}\right)$ stands for a Normal distribution with mean $\mu$ and variance $\sigma^{2}$. The strengths for a corroded and intact pipes are given by:

$$
\begin{aligned}
P_{b i} & =P\left[\frac{1-\left(d_{a} / t\right)}{1-d_{a} /(M t)}\right], \\
P & = \begin{cases}2 t\left(0.9 \sigma_{u}\right) / D & , \sigma_{y}>241 M P a \\
2 t\left(1.15 \sigma_{y}\right) / D & , \sigma_{y} \leq 241 M P a,\end{cases} \\
M & = \begin{cases}\sqrt{1+0.6275\left(l^{2} / D t\right)-0.003375\left(l^{2} / D t\right)^{2}} & , l^{2} / D t \leq 50 \\
0.032\left(l^{2} / D t\right)+3.3 & , l^{2} / D t>50,\end{cases}
\end{aligned}
$$

where $d_{a}$ denotes the average defect depth. Note that the flow stress for high-grade steel $\left(\sigma_{y} \geq 241\right)$ uses the $90 \%$ of the ultimate strength, whereas for low-grade steels the $115 \%$ of the yield strength and that this approach follows a rectangular defect shape.

Chebaro \& Zhou [58] proposed an adjustment of the model errors seeking more accurate predictions for long corrosion defects $(l \geq 0.25 D)$. They also suggested a correlation between the maximum and average corrosion depth based on a lognormal random variable considering that inspections like ILI usually report these measurements rather than the complete profile of each corrosion defect. This approach was omitted for the current review because of its closeness with the CSA criterion.

\section{8. $C U P$}

Shuai et al. [59] proposed a model based on FEM and numerical fitting which was named as CUP. The finite element model was built in ABAQUS considering a regular shape and simplified groove metal loss defects, whereas the failure criterion corresponds when the Von Mises stress reaches the true ultimate strength. The fitting was then proposed using a geometry factor that satisfies boundary conditions for a failure pressure of an intact pipe. 


$$
P_{b}=\frac{2 \sigma_{u} t}{D}\left[1-\frac{d}{t}\left(1-\left(a\left(1-\left(\frac{w}{\pi D}\right)^{2}\right)^{6}+(1-a) \exp \left\{\frac{b l}{\sqrt{D t}}\right\}\right)\left(1-\frac{d}{t}\right)^{c}\right)\right],
$$

where $a=0.1075, b=-0.4103$, and $c=0.2504$ are the obtained fitting parameters. Based on a comparison with 14 burst tests, this model obtained adequate error results against some of the approximations such as RAM and CSA Z662 [59].

\subsection{DNV RP F-101}

This Recommended Practice (RP) emerged from a collaboration between DNV (DET NORSKE VERITAS) and BG Technology through comprehensive databases of burst tests and 3D non-linear finite element simulations. It is preferred for carbon steel pipelines with inner or outer corrosion defects, corrosion seam welds, interacting colonies and metal loss due to routine repairs [15]. Some of the relevant exclusions of this RP include pipelines with grades higher than X80, Stress Corrosion Cracking (SCC) and pipelines where a fracture is expected to occur. This practice is only pertinent for pipelines expected to fail due to plastic collapse [15].

The DNV burst pressure initiates with a simplified approach of a capacity equation using a rectangular shape:

$$
P_{b}=1.05 \frac{2 t \sigma_{u}(1-(d / t))}{(D-t)\left(1-\frac{(d / t)}{M}\right)},
$$

where the Folias factor is given by $M=\sqrt{1+0.31\left(l^{2} / D t\right)}$ and the 1.05 factor comes from laboratory test comparisons. Despite that this approach is conservative for parabolic defects, this capacity pressure is the best approximation for a rectangular shape according to this RP [15].

Among some available extensions of Eq. 30, Liu et al. proposed a revised defect depth to consider the number of defects [60]. DNV proposed additional expressions based on uncertainties of the inspection tool and the pipeline geometry; some relevant factors that depend on the pipeline safety class are proposed as follows [15]:

$$
P_{b}=\gamma_{m} \frac{2 t \sigma_{u}\left(1-\gamma_{d}(d / t)^{*}\right)}{(D-t)\left(1-\frac{\gamma_{d}(d / t)^{*}}{M}\right)},
$$

where $(d / t)^{*}=(d / t)_{\text {meas }}+\epsilon_{d} S t D[d / t]$. Here $S t D[\cdot]$ represents the standard deviation of a given set. Additionally, $\gamma_{m}$, $\gamma_{d}$, and $\epsilon_{d}$ are the factors associated with the model prediction, corrosion depth, and fractile value for the corrosion depth, respectively. These factors depend on the pipeline safety class, inspection absolute accuracy, and the inspection tool implemented (Magnetic Flux Leakage (MFL) or Ultrasound (UT) tools); see Tables 3.2 to 3.12 of the DNV report for more information. For instance, for a normal safety class (i.e., target annual failure probability $<10^{-4}$ ) these factors are given by: $\gamma_{m}=0.77, \gamma_{d}=1+4.6 a-13.9 a^{2}(a=S t D[d / t])$, and $\epsilon_{d}=0$ if $a \leq 0.04$ or $\epsilon_{d}=-1.33+37.5 a-104.2 a^{2}$ if $0.04<a \leq 0.16$ [15]. These two burst pressures are applicable for $0.15 \leq d / t \leq 0.85$.

There is a second burst pressure that is associated with the maximum allowable operating pressure. This approach estimates the failure pressure using the capacity pressure and multiplying it by a design factor. This estimation does not contemplate defects or pipeline geometry uncertainties.

\subsection{FITNET FFS}

This model was developed as a result of a European Fitness for Service Network to assess the structural integrity of pipelines [61] by covering four failure mechanisms: fracture, fatigue, creep, and corrosion [62]. In the corrosion module, the failure pressure for rectangular defects is given by [63]:

$$
P_{b}=\frac{2 \sigma_{u}\left(\frac{1}{2}\right)^{65 \sigma_{y}^{-1}}}{D-t}\left[\frac{1-\frac{d}{t}}{1-\frac{d}{t M}}\right],
$$

where the flow stress $\sigma_{u}\left(\frac{1}{2}\right)^{65 / \sigma_{y}}$ corresponds to the nominal failure stress of an intact pipeline, $\sigma_{y}$ in MPa, once Tresca failure criterion was used with the Hollomon strain-hardening model [64]. $M$ is the same Folias factor used in the approach of ASME B31G (see Table 3). 


\subsection{Approaches proposed based on the Buckingham's $\pi$ theorem}

The approach proposed by Netto et al. [16] was developed based on a combined set of non-linear finite element simulations in three dimensions and experiments with a small scale, both for intact and corroded pipelines [16]. This approach considers the Buckingham's $\pi$ theorem and an iterative process based on least-square errors to fit the best burst pressure expression for $w / D \geq 0.0785,0.1 \leq d / t \leq 0.8$, and $l / D \leq 1.5$ for elliptical defect shapes, where $w$ is the maximum defect width. Burst pressure was almost no influence for defects with $w / D>0.0785$ and $l / D>1.5$ [16].

$$
\begin{aligned}
& P_{b}=P_{b i}\left[1-0.9435\left(\frac{d}{t}\right)^{1.6}\left(\frac{l}{D}\right)^{0.4},\right] \\
& P_{b}=\left[\frac{\left(1.1 \sigma_{y}\right) 2 t}{D}\right]\left[1-0.9435\left(\frac{d}{t}\right)^{1.6}\left(\frac{l}{D}\right)^{0.4}\right] .
\end{aligned}
$$

Note that burst pressure without corrosion defects $\left(P_{b i}\right)$ considers the same calculation for as the one reported in ASME B31G, which is the most used in practice. However, for corroded pipelines, this approach gives significant importance of the defect depth than in the case of ASME B31G. Therefore, ASME B31G predictions underestimate (overestimate) the pipeline condition for shorter (larger) defects in comparison to the Netto approach [45].

This approach was latter updated by Netto in 2010, based on experiments published by Sakakibara et al. [65]. This update was calibrated using shallow $(0.1 \leq d / t \leq 0.2, w / \pi D \leq 0.1)$, moderate deep $(0.2 \leq d / t \leq 0.4, w / \pi D \leq 0.1)$ and narrow defects $(0.4 \leq d / t \leq 0.6, w / \pi D \leq 0.2-0.25 d / t)$. Moderate deep defects with $w / \pi D \geq 0.15-0.25 d / t$ and narrow defects with $w / \pi D \geq 0.1-0.125 d / t$ were set to these width limits [66]. The obtained expression was the following achieving a mean error of $4.4 \%$ with the experimental results [66]:

$$
\frac{P_{b}}{P_{b i}}=\left[\frac{1-d / t}{1-d / t\left(1-(w / \pi D)^{0.4}(l / 10 D)^{0.4}\right)}\right]^{2.675} .
$$

Besides this update, Wang \& Zarghamee [67] proposed a modified version of the initial model from Netto et al. considering its limited pipe configurations. They proposed a model relatively different including pipelines with a diameter greater than $610 \mathrm{~mm}$. The model was developed based on 100 burst test using FEM of pipelines with several configurations. These configurations include diameters from 51 to $2286 \mathrm{~mm}$, wall thickness from 3.42 to 12.7 $\mathrm{mm}$, corrosion depth ratios $d / t$ from 0.1 to 0.85 , length ratios $l / D$ from 0.1 to 2 , and width ratios $w / D$ from 0.09 to 0.18 . The defects follow a rectangular shape that is projected in the surface, but the longitudinal and circumferential directions are associated with elliptical profiles [67]. Their initial results suggest that defect depth and length have a greater impact on the pipeline burst, which could be explained by the dominance of the hoop stress over the axial stress [51].

Considering the aforementioned results and based on a regression analysis, they obtained the following expression for small $(D<610 \mathrm{~mm})$ and large $(D \geq 610 \mathrm{~mm})$ pipes:

$$
\frac{P_{b}}{P_{b i}}= \begin{cases}1-0.886\left(\frac{d}{t}\right)\left(\frac{l}{D}\right)^{0.3} & , \text { for } D<610 \mathrm{~mm} \\ 1-1.120\left(\frac{d}{t}\right)^{1.15}\left(\frac{l}{D}\right)^{0.3} & , \text { for } D \geq 610 \mathrm{~mm} .\end{cases}
$$

The prediction capability of this approach was compared with the ASME B31G approach. The results indicate that both approaches have conservative predictions, but the model of Wang \& Zarghamee leads to significantly smaller errors than those obtained with ASME B31G [67].

There are other similar approaches that use the Buckingham $\pi$ theorem like the model discussed by Mustaffa \& van Gelder [68]. This model considered shallow $(d / t \leq 0.30)$, short $(l / D \leq 0.20)$ and broad $(w / t>0.5)$ defects to achieve the following expression:

$$
\frac{P_{b}}{\sigma_{u}}=\left(\frac{t}{D}\right)^{0.8442}\left(\frac{d}{t}\right)^{-0.0545}\left(\frac{l}{w}\right)^{-0.0104} .
$$




\subsection{Pipe Corrosion Criterion (PCORRC) and some modifications}

PCORRC was developed by Stephens \& Leis from the Battelle company, under the sponsorship of the Line Pipe Research Supervisory Committee of PRC international $[69,70]$. This approach predicts the remaining strength of corroded pipelines that have a moderate to high toughness based on a plastic collapse failure. This strength was determined based on a series of FE analyses of elliptical defects using PCORR, which is a shell-based finite element code to estimate the stress and strain [71]. To propose a simplified burst criterion, Stephens \& Leis considered two limit cases for pipes with infinitesimal defects (unflawed material) and large defects until failure. For the first case, the controlling flow stress was the ultimate strength, whereas the lower case pressure is proportional to the remaining wall thickness [71]. The obtained expression is shown in Eq. 37, which follows a thinner wall pipe with a geometry and material factor that depend on the defect dimensions.

$$
P_{b}=\frac{2 t \sigma_{u}}{D}\left[1-\frac{d}{t}\left(1-\exp \left\{C \frac{l}{\sqrt{r(t-d)}}\right\}\right)\right],
$$

where $C=-0.157$ a parameter obtained from a regression analysis, and $r$ is the pipeline radius. The function in brackets, which is the corresponding Folias factor of this approach, was the expression adopted to relate the ratio between the defect and pipeline failure pressures with the dimensionless parameter $l / \sqrt{R(t-d)}$. This parameter is preferred instead of $l / \sqrt{r t}$ because the remaining wall thickness will guide the defect behavior [71].

According to the authors, this approach is limited to moderate-to-high toughness pipe with blunt defects which fail due to a plastic collapse. They also state that this approach would not be suitable for low toughness materials or pipes operating below their ductile-to-brittle transition temperature [71].

This approach was also implemented by other researchers to evaluate the burst pressure of rectangular corrosion defects in girth or seam welds at X65 [72] and X70 pipelines [73, 74]. These approaches were based on a fitting process based on full-scale burst tests and FEM. Kim et al. [72] used defects up to 75\% of the wall thickness, whereas Yeom and co-workers up to $87.5 \%$ deep $[73,74]$. The expression for the latter approach is shown below:

$$
P_{b}=\frac{2 t 0.9 \sigma_{u}}{D}\left[1-\frac{d}{t}\left(1-\exp \left\{-0.224 \frac{l}{\sqrt{R(t-d)}}\right\}\right)\right],
$$

where $0.9 \sigma_{u}$ and 0.224 parameters were selected for an additional level of conservatism [73, 74]. Kim et al. [72] proposed the same equation, but using a flow factor of $0.95 \sigma_{u_{T}}$ where $\sigma_{u_{T}}$ is the true ultimate stress based on stresshardening curves.

\subsection{Approaches proposed by Phan et al. [75]}

Phan et al. proposed three models using FEM burst tests and the structure of three burst models aforementioned: Netto et al. (Eq.33), NG-18 (Eq. 12), and PCORRC (Eq. 37). For this purpose, they implemented a differential evolution algorithm to minimize the prediction errors. The expressions achieved are the following [75]:

$$
\begin{aligned}
\frac{P_{b}}{P_{b i}} & =1-0.88555\left(\frac{d}{t}\right)^{0.98077}\left(\frac{l}{D}\right)^{0.31053}, \\
\frac{P_{b}}{P_{b i}} & =\frac{1-0.92126 d / t}{1-0.92126 d /(t M)}, \\
\frac{P_{b}}{P_{b i}} & =1-\frac{1.24678 d / t}{1+12.6739 t / l},
\end{aligned}
$$

where the Folias factor follows $M=\left(1+0.06361 l^{2} / D t\right)^{2.75485}$. According to the authors, these models may produce conservative results in comparison to the obtained experimental results. 


\subsection{RAM PIPE REQUAL}

In the late '90s, a collaborative work between Petróleos Mexicanos (PEMEX), Instituto Mexicano del Petróleo (IMP), and the U.S. Minerals Management Service directed an approach for Risk Assessment and Management (RAM) for the reassessment and requalification of marine pipelines [76]. This approach was identified as RAM PIPE REQUAL, and its initial evaluation for the median burst pressure for a corroded pipeline is as follows [77]:

$$
P_{b}=2.4 \frac{t \sigma_{u}}{(D-t) S C F} .
$$

where $S C F$ is a stress concentration factor representing the ratio between the maximum and nominal hoop stresses. It depends on the pipeline radius $(r)$ as follows:

$$
S C F=1+2 \sqrt{\frac{d}{r}} .
$$

One of the most important features about this model is that it omits the length of the corrosion defects because of the difficulty to estimate the metal loss area accurately for uninstrumented pipelines [76]. According to the second report of the project, the stress concentration factor includes the width inherently in its formulation because of the use of the pipe radius. Based on the 151 burst tests, this report also states that no explicit dependency was obtained for the defects length or area with the burst pressure [77].

This approach was modified to evaluate the capacity of corroded pipelines to withstand their net pressures (i.e., $P-P_{o}$ ) as follows:

$$
P_{b}=2.2(t-d) \frac{\sigma_{u}}{(D-t) S C F} .
$$

note that this modified version considers the minimum wall thickness of each defect instead of the nominal thickness. The last modification of this model includes a working stress reassessment $f$ for its reliability formulation:

$$
P_{b}=2 f \sigma_{u} \frac{(t-d)}{(D-t) S C F},
$$

This factor can be estimated based on the percentiles and reported uncertainty of the pipeline burst pressure and operating pressure [76, 78]. The model described by Eq. 43 was considered in this work unless stated otherwise.

\subsection{Approaches including strain-hardening models}

Different approaches have been proposed considering the pipeline strain hardening behavior for different pipelines toughness. Zhu \& Leis [79] considered yield-to-ultimate ratios for Grade B and X80 pipelines to develop a plastic instability model with corrosion defects. Based on Hollomon strain model and the material true strain and stress, the burst pressure was obtained:

$$
P_{b}=\frac{4}{(3)^{(n+1) / 2}} \frac{t}{D} \sigma_{u}\left[1-\frac{d}{t}\left(1-\exp \left\{-0.157 \frac{l}{\sqrt{R(t-d)}}\right\}\right)\right],
$$

where $n=-0.0319+\sqrt{0.0856\left(\sigma_{u} / \sigma_{y}\right)-0.0846}$ the hardening exponent obtained from the X80 pipeline [79]. Afterwards, Zhu proposed a new material failure criterion based on FEM for X65 pipelines due to a modified Von Mises criteria [80]:

$$
P_{b}=\left(\frac{2+\sqrt{3}}{4 \sqrt{3}}\right)^{n+1} \frac{4 t}{D} \sigma_{u}\left[1-\frac{d}{t} f_{L}\right]
$$

where:

$$
f_{L}=1-\frac{1}{1+0.1385(l / \sqrt{D t})+0.1357\left(l^{2} / D t\right)} .
$$

Another approach was proposed by Ma et.al [81] for high-toughness pipelines considering a plastic deformation criterion and using elliptical shaped defects with spherical ends. This model was developed based on regression 
analysis from 195 FEM simulations of corroded pipelines with different material properties (i.e., X70 and X80), whose length varied from $25 \mathrm{~mm}$ to $2000 \mathrm{~mm}$, their depth from $20 \%$ to $60 \%$ of the wall thickness, and they had a constant width. The expression obtained for the burst pressure in corroded pipelines is the following:

$$
P_{b}=\frac{4}{3^{(n+1) / 2 n}} \frac{t}{D} \sigma_{u}\left\{1-\frac{d}{t}\left[1-0.7501 \exp \left(\frac{-0.4174 l}{\sqrt{D t}}\right)\left(1-\frac{d}{t}\right)^{-0.1151}\right]\right\} .
$$

The first term of this equation corresponds with the failure pressure of an intact pipeline based on the Von Mises criterion and the Ramberg-Osgood as the strain-hardening model. This hardening model was omitted in approaches for high toughness pipes such as Choi et al .[51].

This model was validated with 79 additional burst tests of low, middle, and high toughness pipes showing an adequate prediction agreement. The validation tests with other recognized approaches like ASME B31G, DNV RP F-101, PCORRC, and Choi et al. [51] model indicated that this model is suitable for high-to-middle toughness pipes, but not for low-toughness [81].

Other similar approaches were proposed by Keshtegar \& Miri [82] and Ghani et al. [83] for X65 corroded pipelines based on the structure of the PCORRC's model, and the ASSY and Tresca failures criteria, respectively. These criteria are aimed to evaluate moderate to high toughness pipelines, whereas conservative results would be achieved for low toughness.

\subsection{SHELL92}

The SHELL92 burst model is a modification of the ASME B31G with more conservative predictions by implementing rectangular defect shapes. This approach is used up to $85 \%$ of the wall thickness of the pipe [84, 85]:

$$
P_{b}=\frac{2 t\left(0.9 \sigma_{u}\right)}{D}\left[\frac{1-\frac{d}{t}}{1-\frac{d}{t M}}\right],
$$

where the Folias factor is given by $M=\sqrt{1+0.8\left(\frac{l^{2}}{D t}\right)}$.

\subsection{Approach proposed by Zhang et al. [86]}

Zhang et al. proposed a burst model based on a series of 27 FEM simulations of a X65 girth welded pipeline with rectangular corrosion defects [86]. For this purpose, they used regression analysis taking into account the influence of normalized defect dimensions (i.e., $d / t, l / \sqrt{D t}$ ) on the burst pressure with errors smaller than $7.5 \%$. The expression obtained is shown below:

$$
P_{b}=0.1827\left(\frac{d}{t}\right)^{-0.0968}\left(\frac{l}{\sqrt{D t}}\right)^{-0.0536} \sigma_{u}^{-0.8952} .
$$

This approach was compared with the approach proposed by Ma et al. [81], obtaining similar predictions for three strength cases for girth welds based on the yield strength of the pipe metal. Therefore, this approach was not considered for further comparisons.

\section{Burst model comparison}

To the authors' knowledge, academic and industry literature use almost surely the aforementioned approaches to predict burst pressures. Other approaches that were not included in this review because they are specific for girth welds (see the review in [21]), they combine external forces [87] or they require data training [21]. For instance, Keshtegar $\&$ el Amine Ben Seghier recently proposed a model using modified response surface methodology based on harmony search [21]. This approach predicts the burst pressure by implementing non-linear polynomial basic functions, which minimize the mean square errors from records of a test dataset. Indeed, the predictions of this model depend on this dataset, so it was omitted for this work.

Regarding the burst models mentioned above, they have some limitations in their application, which in turn, can trigger conservative results depending on the pipeline geometry (e.g., diameter, wall thickness), corrosion dimensions 
(depth, length, and width) or the properties of the construction materials of the steel (e.g., yield and ultimate strength). Therefore, this section aims to compare them based on their failure criteria, metal loss acceptability, failure probability, mean time to failure, and prediction errors.

\subsection{Failure criteria comparison}

Table 4 presents the characteristics of each model in terms of the flow stress, defect idealization, material restriction, and definition of long defects.

Table 4: Burst model summary properties

\begin{tabular}{|c|c|c|c|c|}
\hline Model & Flow stress & Defect shape & Material restriction & Long defect limit \\
\hline ASME B31G [14] & $1.1 \sigma_{y}$ & Parabolic & $\begin{array}{l}\text { Low toughness pipes (be- } \\
\text { low X56) }\end{array}$ & $l^{2} / D t=20$ \\
\hline ModB31G [14] & $\sigma_{y}+69 \mathrm{MPa}$ & Mixed shape & $\begin{array}{l}\text { Low-to-moderate tough- } \\
\text { ness pipes (below X65) }\end{array}$ & $l^{2} / D t=50$ \\
\hline RSTRENG [14] & $\sigma_{y}+69 \mathrm{MPa}$ & Effective area & No & $l^{2} / D t=50$ \\
\hline RPA [49] & $\sigma_{y}+69 \mathrm{MPa}$ & Rectangle + Parabolic & $\begin{array}{l}\text { Low-to-moderate tough- } \\
\text { ness pipes (below X65) }\end{array}$ & $l^{2} / D t=20$ \\
\hline Choi et al. [51] & $0.9 \sigma_{u}$ & Elliptical & $\begin{array}{l}\text { High toughness pipes } \\
\text { (X65) }\end{array}$ & $l^{2} / D t=18$ \\
\hline Chen et al. [52] & $\sigma_{u}$ & Elliptical & $\begin{array}{l}\text { High toughness pipes } \\
\text { (X80 to X90) }\end{array}$ & $l^{2} / D t=25$ \\
\hline CPS [53] & $0.9 \sigma_{u}$ & Step shape & $\begin{array}{l}\text { Moderate toughness pipes } \\
\text { (X42 to X55) }\end{array}$ & - \\
\hline CSA [3] & $0.9 \sigma_{u}$ for $\sigma_{y}>241 \mathrm{MPa}$ & Rectangular & $\begin{array}{l}\text { Low-to-moderate tough- } \\
\text { ness pipes (below X65) }\end{array}$ & $l^{2} / D t=50$ \\
\hline $\begin{array}{l}\text { Chebaro \& } \\
\text { Zhou [58] }\end{array}$ & $\begin{array}{l}1.15 \sigma_{y} \text { for } \sigma_{y} \leq 241 \mathrm{MPa} \\
0.9 \sigma_{u} \text { for } \sigma_{y}>241 \mathrm{MPa} \\
1.15 \sigma_{y} \text { for } \sigma_{y} \leq 241 \mathrm{MPa}\end{array}$ & Rectangular & No & $l=0.25 D$ \\
\hline CUP [59] & $\sigma_{u}$ & Regular shape - groove & $\begin{array}{l}\text { Moderate toughness pipes } \\
\text { (X46 to X60) }\end{array}$ & - \\
\hline DNV [15] & $\sigma_{u}$ for CP approach & Rectangular & $\begin{array}{l}\text { Excluding high toughness } \\
\text { pipes (X80) }\end{array}$ & - \\
\hline FITNET FFS [64] & $\begin{array}{l}\gamma_{m} \sigma_{u} \text { for a given safety level } \\
\sigma_{u}(1 / 2)^{65 \sigma_{y}^{-1}}\end{array}$ & Rectangular & NR & $l^{2} / D t=20$ \\
\hline Ma et al. $[81]^{* *}$ & $2 \sigma_{u} / 3^{(n+1) / 2 n}$ & Elliptical & $\begin{array}{l}\text { Excluding low toughness } \\
\text { pipes }\end{array}$ & - \\
\hline Netto et al. [16] & $1.1 \sigma_{y}$ & Elliptical & $\begin{array}{l}\text { Moderate-to-high tough- } \\
\text { ness pipes (X52 to X77) }\end{array}$ & - \\
\hline Wang et al. [67] & $1.1 \sigma_{y}$ & Rectangular + Elliptical & No & - \\
\hline PCORRC [71] & $\sigma_{u}$ & Elliptical & $\begin{array}{l}\text { Moderate-to-high tough- } \\
\text { ness pipes }\end{array}$ & - \\
\hline Phan [75] & $\sigma_{u}$ & Rectangular & $\begin{array}{l}\text { Moderate-to-high tough- } \\
\text { ness pipes }\end{array}$ & - \\
\hline RAM [76] & $\sigma_{u}$ & & NR & - \\
\hline SHELL92 [85] & $0.9 \sigma_{u}$ & Rectangular & NR & - \\
\hline Yeom et al. $[73,74]$ & $0.9 \sigma_{u}$ & Rectangular & $\begin{array}{l}\text { High toughness pipes } \\
\text { (X65 to X70) }\end{array}$ & - \\
\hline Zhu et al. [79]* & $2 \sigma_{u} / 3^{(n+1) / 2}$ & Rectangular & No & - \\
\hline Zhu et al. [80]* & $2 \sigma_{u}\left(\frac{2+\sqrt{3}}{4 \sqrt{3}}\right)^{n+1}$ & Rectangular & $\begin{array}{l}\text { Moderate-to-high tough- } \\
\text { ness pipes (X65 to X80) }\end{array}$ & - \\
\hline
\end{tabular}

This table shows that elliptical defect shapes were preferred for approaches using FEM simulations (e.g., Choi, Chen, Netto, Wang, PCORRC, and Ma), whereas those from codes like ASME, CSA, and DNV commonly proposed rectangular defect shapes for an additional level of conservatism in pipeline assessment. Regarding the flow stress, which is associated with the corresponding plastic collapse of the pipe, it lies within the yield and ultimate strengths except for the models that include the strain-hardening coefficients because they approximate the true strain-stress curve of the steel. This table also indicates that the reviewed models are appropriate for a certain material toughness: 
- Low toughness pipes (Below X55): ASME B31G, ModB31G, RPA, CPS, CSA, CUP, DNV, Netto RAM, and SHELL;

- Moderate toughness (X55 to X65): ModB31G, RPA, Choi, CSA, CUP, DNV, Ma, Netto, Wang, PCORRC, Phan, Yeom, and Zhu; and

- High toughness (above X65): Chen, Ma, Netto, PCORRC, Phan, Yeom, Zhu.

There are some models with not announced restrictions in the public literature like Fitnet FFS, RAM, and SHELL that can be used in principle for any pipeline bearing in mind this limitation.

Material restrictions should be considered because inappropriate model selection may produce exaggerated conservative results. An arbitrary selection inherently assumes that the prediction capabilities of a model remain unchanged although the model was calibrated with specific burst tests. To properly compare the models level of conservatism, the ratio of the flow-to-ultimate strength was determined for each material reported by the API 5L and depicted in Fig. 6. According to Benjamin, an approach with a smaller ratio would be more conservative [42]. Note that the ASME B31G, Netto and Wang approaches $\left(1.1 \sigma_{y}\right)$ decrease their level of conservatism with the steel toughness obtaining flow stresses close to the reported ultimate strength. Considering that approaches from Netto and Wang were designed for moderate-to-high toughness pipes, this result suggests that both approaches are more suitable than standards like ASME and CSA, as it was previously pointed out by Hasan et al. [20] and Teixeira et al. [45]. Note also that the modifications of ASME (i.e., ModB31G, RSTRENG, and RPA) were proposed to decrease the level of conservatism in low toughness pipelines, which is the range of applicability of this model. Finally, Fitnet FFS approach $\left(\sigma_{u}(1 / 2)^{65 \sigma_{y}^{-1}}\right)$ could be too protective with a failure threshold lower than ASME for moderate-to-high toughness pipelines, which prevents it to be selected in these cases.

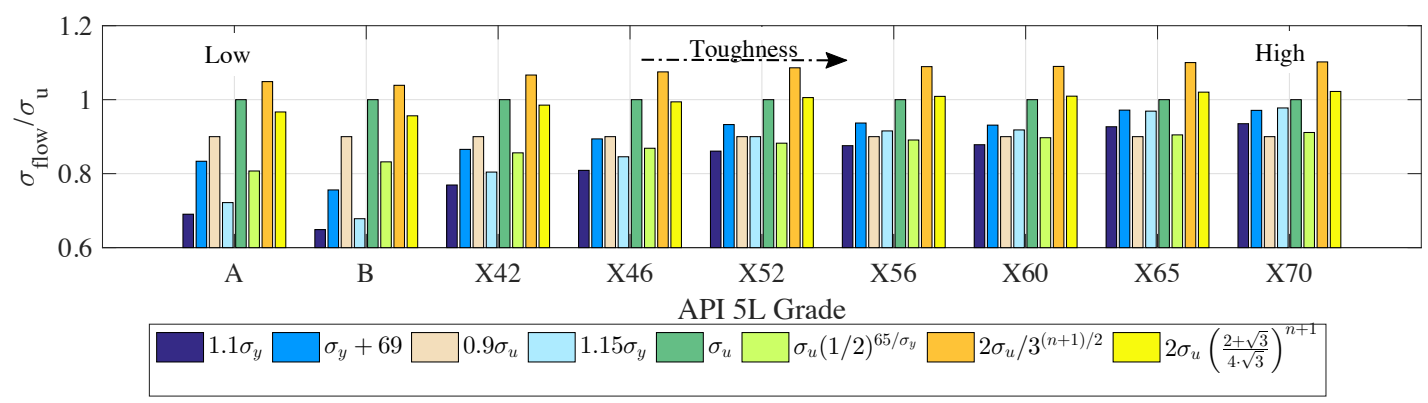

Figure 6: Flow-to-ultimate stress ratio comparison

\subsection{Metal loss acceptability}

The failure criteria described through the flow stress is restricted to intact pipelines. Defect information like the shape idealization or its dimensions is not considered yet. To evaluate these parameters in the comparison, the acceptable depth to withstand the pipe maximum operating pressure (MAOP) was determined for each approach given a defect length. The latter considering that these parameters affect appreciably the burst pressure [51], particularly the defect depth in models like Netto and ASME B31G [45]. For this purpose, three case studies are proposed for a low, moderate and high toughness pipelines considering the toughness restrictions of each model, and a MAOP with the $72 \%$ of allowable stress. The properties of each case are presented in Table 5, whereas Figure 7 depicts the acceptable diagram using dimensionless variables $d / t$ and $l^{2} / D t$ in which the burst pressure would rise up to the operating pressure for low (Figure 7a-b), moderate (Figure 7c-d), and high (Figure 7e-f) toughness pipes.

A defect is acceptable according to a burst model if its defect depth is lower than the reported in Fig. 7 given a specific $l^{2} / D t$. Note these figures also include long defects like in the case of ASME B31G, where exaggerated conservative results are obtained by requiring defects depth be lower than $0.4 t$ to prevent a burst (Fig. $7 \mathrm{~b}$ ). These figures also show that RAM approach can be considered as a lower boundary of acceptable defects due to its independence with defect length. 
Table 5: Case studies for acceptable diagrams.

\begin{tabular}{llll}
\hline \multicolumn{1}{c}{ Parameter } & \multicolumn{1}{c}{$\begin{array}{c}\text { Low } \\
\text { toughness }\end{array}$} & \multicolumn{1}{c}{$\begin{array}{c}\text { Moderate } \\
\text { Toughness }\end{array}$} & $\begin{array}{c}\text { High } \\
\text { Toughness }\end{array}$ \\
\hline$D[\mathrm{~mm}]$ & 304.8 & 610 & 1016 \\
$t[\mathrm{~mm}]$ & 6.35 & 7.1 & 18.4 \\
$\sigma_{y}[\mathrm{MPa}]$ & 320 & 450 & 552 \\
$\sigma_{u}[\mathrm{MPa}]$ & 435 & 535 & 650 \\
$E[\mathrm{MPa}]$ & 207000 & 207000 & 206000 \\
MAOP $[\mathrm{MPa}]$ & 9.6 & 7.54 & 14.39 \\
Pipe material & $\mathrm{X} 46$ & $\mathrm{X} 65$ & $\mathrm{X} 80$ \\
\hline
\end{tabular}

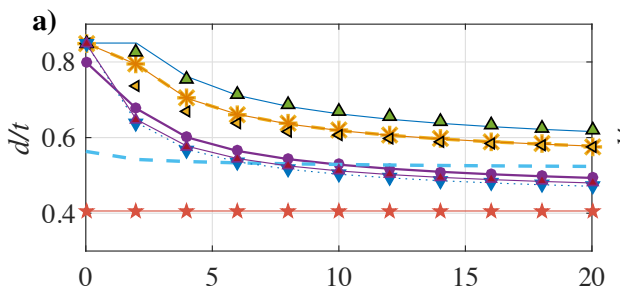

b)
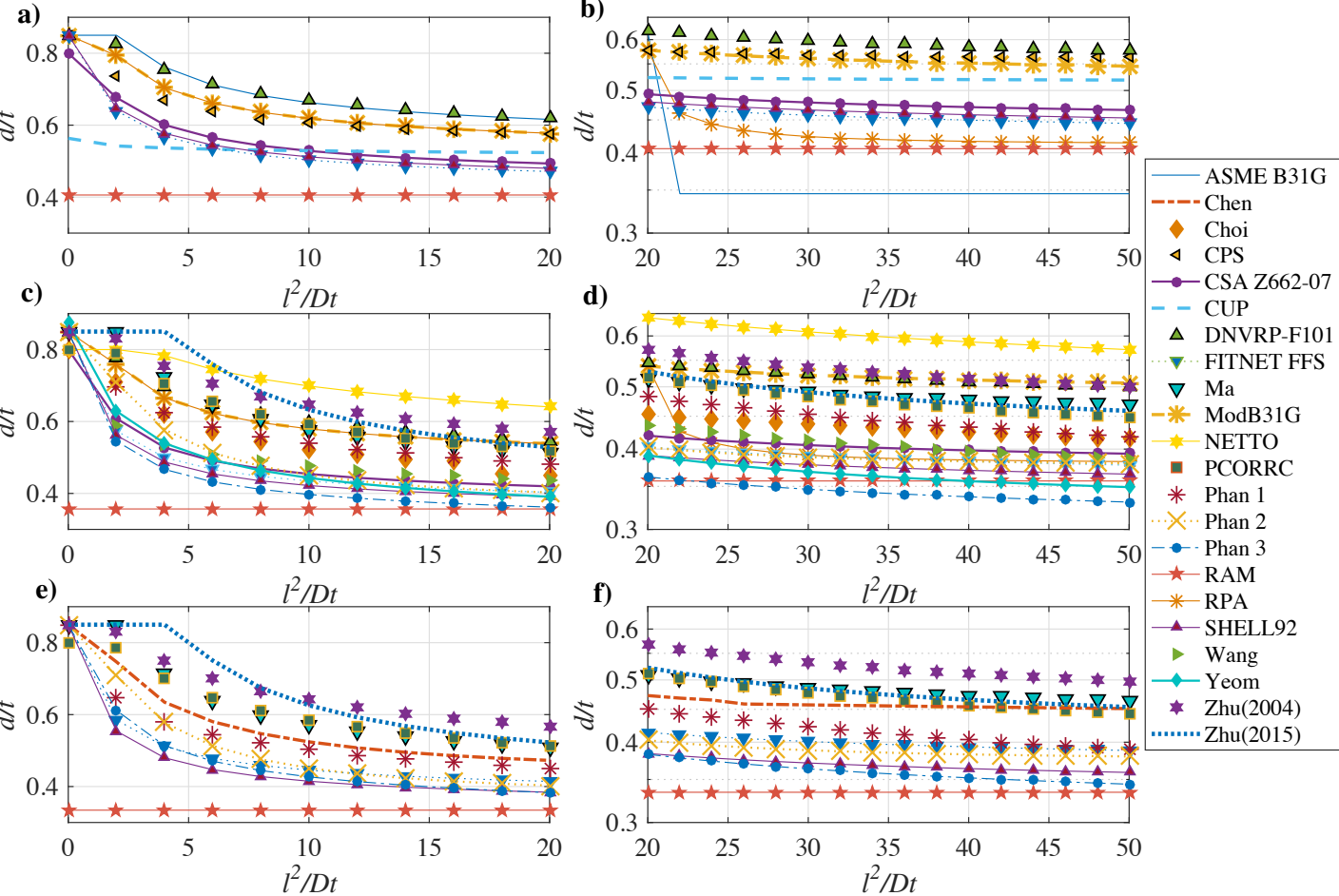

Figure 7: Acceptable diagram for: a) low, b) low (continued), c) moderate, d) moderate (continued), e) high, and f) high (continued) toughness

In regard of the three case studies, the results show that the RPA approach increments the level of conservatism of ModB31G for long defects in low-to-moderate toughness pipes almost until the prediction of RAM, whereas the approaches of Choi and Chen presents less noticeable changes for moderate and high toughness pipelines, respectively. These figures also indicate some common performances among the models reviewed. For low toughness pipes, there are three clear approaches with similar behaviors: i) CPS, DNV, and ModB31G; ii) CSA, Fitnet, and SHELL; and iii) the approach of CUP that lies between them. Figure 7a also shows that the CUP approach is overly conservative for almost impact pipelines with an acceptable depth lower than $0.6 t$ to prevent a burst. These results indicate that approaches like ASME B31G, RAM, and CUP would overestimate the real strength of the pipeline and unnecessary intervention can be implemented. However, the CUP model could be an interesting approach for long defects with $l^{2} / D t>20$. For moderate toughness pipes, Figure 7c-d suggest two model clusters: i) ModB31G, DNV, Ma, PCORRC, and Zhu; ii) CSA, Phan(1-2), SHELL, Yeom, and Wang. Two additional models lie between these clusters, i.e., Phan (1) and Choi, and finally, the model of Netto that is not conservative at all, except for short defects with the approach of Zhu. These results indicate that approaches like DNV, Ma, PCORRC, and Zhu are interesting models to be considered for pipes with a moderate toughness. Finally, Figure 7e-f present the results for high toughness pipes exposing two model clusters: i) Chen, PCORRC, Ma, and Zhu; ii) Phan and SHELL, which again confirms that the 
same approaches as for moderate toughness pipes including the model of Chen.

Similar results were determined by other comparisons based on calculated failure probabilities. Hasan et al. [20] compared the standards ASME B31G, DNV RP F-101 (the capacity -CP- and the maximum allowable pressure -MOPapproaches), CSA Z662-07, and the approach of Netto et al. [16] using Monte Carlo simulations and First Order Second Moment (FOSM) methods. Their results indicate that the DNV (MOP) and CSA approaches are conservative in comparison to ASME B31G, Netto, and DNV (CP). Additionally, they concluded that the standard DNV RP F-101 (CP) is adequate for moderate to high toughness pipelines, whereas the ASME B31G approach could be applicable for any toughness steel based on sensitivity analysis of the failure probability and burst pressure. They recommended the DNV approach for new hardened pipes and ASME B31G or CSA Z662 for both new and old pipes because of their closeness with the results obtained with the model of Netto and co-workers. Another interesting comparison was developed by Caleyo et al. [88] using the ASME B31G, Modified B31G, PCORRC, DNV RP -A version launched in 1999 without the factor 1.05 in Eq. 30-, and SHELL92 approaches. They evaluated several influences on the failure probability and the rate of repairs of a pipeline: the methods to calculate the failure probability, the resistance/load variables distribution, and these coefficients of variation of these distributions. The results of Caleyo et al. [88] showed that the SHELL92 and ASME B31G approaches, respectively, obtained the highest and lowest failure probabilities, which could be attributed to the significance of the defect depth, length, and the operating pressure for the ASME B31G approach [88]. Furthermore, they concluded that defects which depths are around $15 \%$ of the wall thickness depend significantly on the burst model, whereas depths about $50 \%$ of the wall thickness this dependence is highly undetected. In this case, it can be said that the difference in burst predictions are almost infinitesimal for longer defects.

\subsection{Failure probability comparison}

To evaluate now the sensitivity of each approach with the defect depth, the failure probability of the reviewed models were determined by implementing the case study reported in Hasan et al. [20]; i.e. an API 5L X65 pipeline with the properties shown in Table 6, which is subject of a degradation process predicted by the SwRI model [89].

Table 6: Case Study reported by Hasan et al. [20].

\begin{tabular}{lllllll}
\hline Parameter & $\sigma_{u}[\mathrm{MPa}]$ & $\sigma_{y}[\mathrm{MPa}]$ & $D[\mathrm{~mm}]$ & $t[\mathrm{~mm}]$ & $P[\mathrm{MPa}]$ & $l[\mathrm{~mm}]$ \\
\hline Mean & 531 & 448 & 713 & 20.24 & 17.12 & 340 \\
COV & 0.05 & 0.07 & 0.001 & 0.001 & 0.08 & 0.5 \\
Distribution Lognormal & Lognormal & Normal* & Normal* & Gumbel & Weibull \\
\hline *Truncated at 0. & & & & &
\end{tabular}

The failure probability was then calculated with Monte Carlo simulations using an operating pressure based on the yield pressure (for a defect-free pipe) and a safety factor of $72 \%$. The obtained results are depicted in Fig 8, where the model of RAM using Eq. 42 is also included. This figure shows similar performances regarding a certain failure $\left(P_{f} \approx 1\right.$ about $\mathrm{t}=30$ years) with a relatively different evolution for the CSA Z662 approach. Besides, the results indicate that RAM, SHELL92, Fitnet FFS, Wang's model and CSA Z662 (after 10 years) may obtain conservative burst failure predictions in comparison with the other approaches. Note that a failure probability of 0.5 for these approaches is reached from 8 (RAM) to 12 (SHELL) years, which is lower than the 17 years predicted by the Model of Netto. The early failure of CSA was unexpected considering the results of Zhou \& Huang [19]; however, a similar pattern was obtained using information from In-Line inspection [90]. This result may be attributed to the conservatism of moderate-to-high toughness pipelines mentioned by Hasan et al. [20]. Specifically for the RAM predictions, the conservative results are linked with the use of minimum wall thickness instead of the nominal wall thickness as the other burst pressure models. The failure probability of RAM-Med is clearly less conservative based on the reliability in comparison to the other approaches.

Regarding the burst pressure, Table 7 depicts the results for the mean and coefficient of variation (COV) of each model. The majority of the evaluated models follow a common pattern starting near $30 \mathrm{MPa}$ for intact pipelines and reaching a final burst pressure about $16 \mathrm{MPa}$, after 15 years of corrosion degradation. Bearing in mind that DNV is one of the more accurate burst models for defect-free pipes, the results shown in Table 7 for the first evaluating year, reveal that approaches like Chen, CPS, Ma, RAM, and Zhu may also have good predictions. However, the models of RAM and Chen are more sensitive to depth metal loss by obtaining a difference of $11 \mathrm{MPa}$ between RAM and DNV 


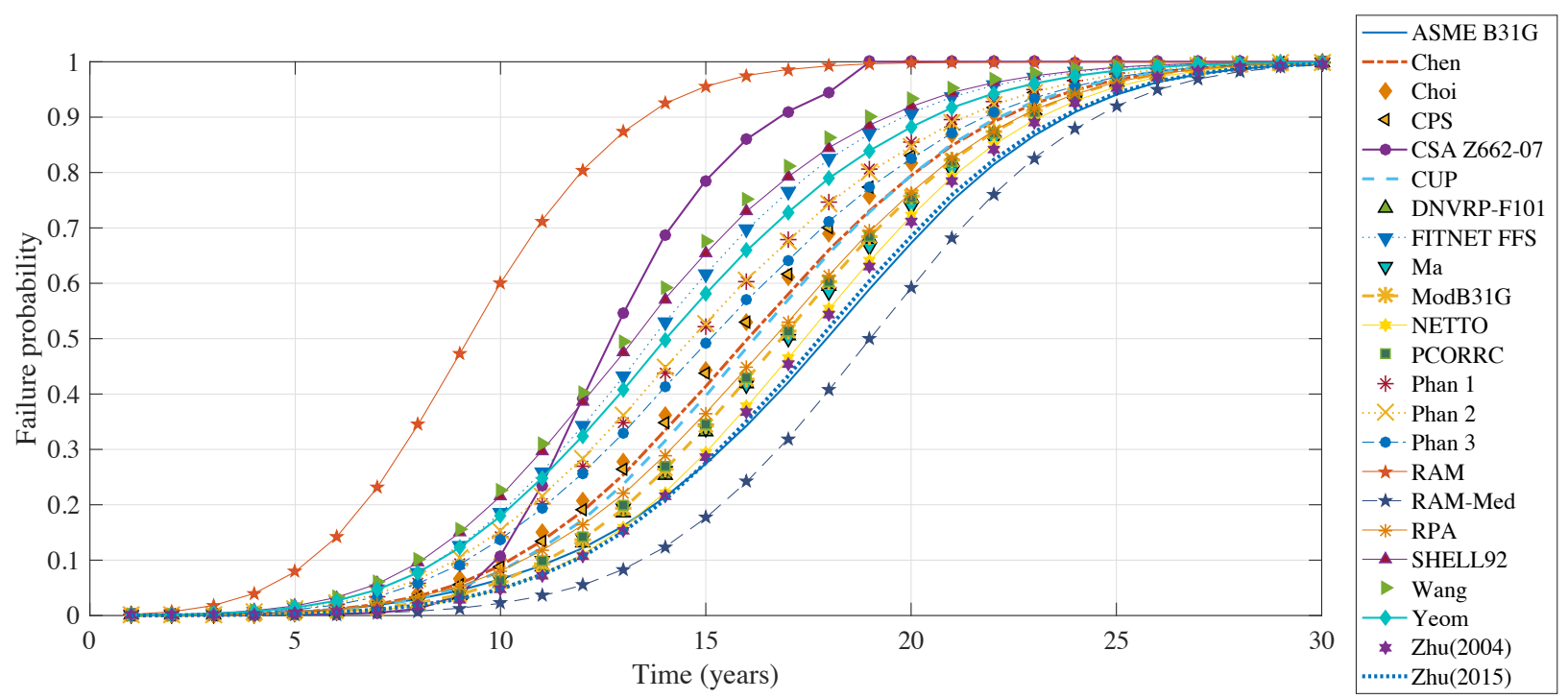

Figure 8: Failure Probability comparison for the selected models

after 15 years of evaluation, so their predictions may be too conservative for pipelines with deeper defects. Indeed, the COV presented in Table 7 shows that Netto and RAM have the lowest and highest COV for burst predictions, respectively, which confirms the above statement. The COV propagation rates were almost constant for DNV, FFS, Phan(2), Yeom, SHELL, Zhu (2004), and PCORRC; increasing for CSA, Choi, and CPS; and decreasing for ASME B31G, Chen, CUP, Ma, ModB31G, Phan(1-3), RAM, RPA, Wang, and Zhu(2015). In addition, the propagation results of the models Phan were close to the structure they were developed, i.e., Netto (Phan 1), FFS (Phan 2), and PCORRC (Phan 3), which was expected. The aforementioned results would suggest that models with decreasing or stable propagation rates are suitable for the predictions of the burst pressure. In case of a moderate toughness pipe like the case study, models like DNV, Ma, Netto, PCORRC, and Zhu can be suggested in advance.

Table 7: Mean and COV results of the predicted burst pressure

\begin{tabular}{lllll|llll}
\hline Parameter & \multicolumn{7}{c}{ Mean $P_{b}$} \\
\hline Year & 1 & 5 & 10 & 15 & 1 & 5 & 10 & 15 \\
\hline ASMEB31G & 27.50 & 25.44 & 22.80 & 20.42 & 0.03 & 0.08 & 0.13 & 0.18 \\
Chen & 33.58 & 28.75 & 23.24 & 18.97 & 0.04 & 0.10 & 0.17 & 0.22 \\
Choi & 24.75 & 23.71 & 21.17 & 18.12 & 0.10 & 0.07 & 0.13 & 0.20 \\
CPS & 33.77 & 29.73 & 24.23 & 19.06 & 0.04 & 0.09 & 0.18 & 0.26 \\
CSA & 26.81 & 24.11 & 19.97 & 14.58 & 0.03 & 0.06 & 0.12 & 0.24 \\
CUP & 29.44 & 26.42 & 22.45 & 18.86 & 0.03 & 0.08 & 0.14 & 0.19 \\
DNV & 32.02 & 29.42 & 25.48 & 21.37 & 0.03 & 0.08 & 0.16 & 0.24 \\
FFS & 27.39 & 24.42 & 20.21 & 16.13 & 0.03 & 0.10 & 0.18 & 0.27 \\
Ma & 32.18 & 28.21 & 23.66 & 20.16 & 0.03 & 0.09 & 0.15 & 0.19 \\
ModB31G & 28.80 & 26.40 & 23.07 & 19.90 & 0.03 & 0.07 & 0.13 & 0.18 \\
Netto & 27.81 & 26.25 & 23.23 & 20.08 & 0.02 & 0.06 & 0.11 & 0.15 \\
PCORRC & 29.60 & 27.18 & 23.72 & 20.24 & 0.02 & 0.08 & 0.14 & 0.21 \\
Phan 1 & 27.14 & 23.88 & 20.08 & 17.04 & 0.03 & 0.09 & 0.13 & 0.16 \\
Phan 2 & 27.36 & 24.67 & 21.03 & 17.60 & 0.03 & 0.10 & 0.18 & 0.26 \\
Phan 3 & 27.22 & 24.15 & 20.53 & 17.59 & 0.03 & 0.09 & 0.15 & 0.20 \\
RAM & 30.04 & 22.12 & 15.19 & 10.34 & 0.08 & 0.16 & 0.25 & 0.30 \\
RPA & 28.78 & 26.26 & 22.83 & 19.58 & 0.03 & 0.08 & 0.15 & 0.21 \\
SHELL & 26.48 & 23.61 & 19.54 & 15.60 & 0.03 & 0.10 & 0.18 & 0.27 \\
Wang & 27.30 & 23.86 & 19.19 & 15.16 & 0.03 & 0.10 & 0.18 & 0.23 \\
Yeom & 26.51 & 23.81 & 20.05 & 16.41 & 0.03 & 0.09 & 0.17 & 0.25 \\
Zhu (2004) & 32.39 & 29.74 & 25.96 & 22.15 & 0.02 & 0.08 & 0.14 & 0.21 \\
Zhu (2015) & 30.10 & 27.43 & 24.27 & 21.71 & 0.03 & 0.08 & 0.14 & 0.19 \\
\hline & & & & & & & &
\end{tabular}


The above results can be associated with the conservative bias inherent in the models following NG-18 equations (e.g., ASME B31G, Mod B31G). According to Cosham \& Hopkins [44], these models were developed from Vshaped notches tests, so there are some discrepancies for blunt defects. This would imply that they are suitable for low toughness pipelines, on the contrary to recent approaches such as PCORRC and DNV which implemented FEM simulations of blunt defects. These two approaches are adequate for modern pipelines that have a higher toughness such that the failure of blunt defects is controlled by plastic collapse [44].

\subsection{Mean time to failure comparison}

For the next comparison, the mean time to failure for each model was determined using three corrosion rates (low, moderate and high) that have a uniform and localized degradation processes, following the reported by Sahraoui et al. [91]:

$$
d_{T}=\left(k_{U C}+\alpha_{L C} \Delta k_{L C}\right) T^{n_{c}}, \quad l_{T}=\gamma_{L C} d_{T},
$$

where $d_{T}$ and $l_{T}$ are the defect depth and length at time $T ; k_{U C}$ and $n_{c}$ are parameters associated to an uniform corrosion; $\Delta k_{L C}$ is the rate of localized corrosion; $\alpha_{L C}$ is the ratio of localized corrosion defects (assumed as unity as in [91]); and $\gamma_{L C}$ is the length-to-depth ratio of localized corrosion. The random variables taken for the three cases are shown in Table 8. The pipeline parameters were obtained from the three toughness cases in Table 5 using the coefficients of variation proposed by Sahraoui et al. [91]; i.e. $C O V_{D}=0.03, C O V_{t}=0.05, C O V_{\sigma_{y}}=0.0669$, $C O V_{\sigma_{u}}=0.0669$, and $\operatorname{COV}_{P}=0.1$.

Table 8: Corrosion case studies. Adapted from [91]

\begin{tabular}{llll}
\hline \multirow{2}{*}{ Parameter } & \multicolumn{3}{c}{ Corrosion rate } \\
\cline { 2 - 4 } & Low & Moderate & High \\
\hline$k_{U C}$ & $0.14(0.1)$ & $0.37(0.1)$ & $0.62(0.1)$ \\
$\Delta k_{L C}$ & $0.14(0.2)$ & $0.37(0.2)$ & $0.62(0.2)$ \\
$n_{c}$ & 0.53 & 0.53 & 0.53 \\
$\gamma_{L C}$ & $50(0.04)$ & $50(0.04)$ & $50(0.04)$ \\
\hline \multicolumn{2}{l}{ Normal distributed variables - COV in parenthesis }
\end{tabular}

The time to failure was determined by the first time when the limit state function was negative. Based on 5000 Monte Carlo sample paths from these corrosion rates, the probability density function (pdf) of the time to failure was obtained as shown in Fig. 9. This figure depicts only the model selected by the toughness classification in low, moderate, and high toughness. Table 9 presents the mean time to failure of each approach. The results show that a greater corrosion rate reduces the time to failure, as it was discussed above with the failure probability. This figure also suggests that high toughness pipelines have a lifetime 4 times greater than moderate or low toughness pipes, whereas the difference between a low and moderate toughness pipes are almost 2 times. The shapes of these pdfs are almost symmetrical with coefficients of variations (COV) near to 0.2. Regarding the results for each toughness classification, the CUP approach seems to be slightly conservative than the DNV and CPS models for the low toughness case; the results for moderate toughness case show a homogeneous performance between all the approaches; and finally, the approaches of Chen and Zhu (2004) are the more and less conservatives for high toughness, respectively.

Based on the corrosion rate and pipe toughness categories, Table 9 heat-maps also shows that there are significant differences in the predicted mean time to failure. For instance, for a low toughness and corrosion, the Wang approach predicts a mean failure in 35.8 years, whereas it is 94.4 years for the approach of Zhu (2004). This difference of 59 years represents a matter of concern for decision-makers that aim to support new interventions. These differences were also obtained at a low corrosion rate for moderate and high toughness pipes. Following the heat-maps, it can be differentiated some interesting patterns like the one composed by Phan1-3, RAM, FFS, CUP, Yeom, and Wang, which predict lower mean time to failure for all corrosion rates and pipe toughness $(\leq 50 \%)$. Also, the predictions from DNV and the strain-hardening approaches (i.e., Zhu $(2004,2015)$ ) have the highest mean time to failure in the majority of cases, whereas models such as Ma, ModB31G, Chen, PCORRC, and RPA lie between the maximum and minimum predictions. These patterns can be explained considering the defect idealization and the fact that some models like Phan1-3 were obtained based on methods that minimized the error predictions from a set of experimental tests. Actually, Phan and co-workers have pointed out possible conservative results with their burst models [75]. Recall that the RAM model uses the minimum wall thickness in the burst estimation instead of the nominal, so lower 

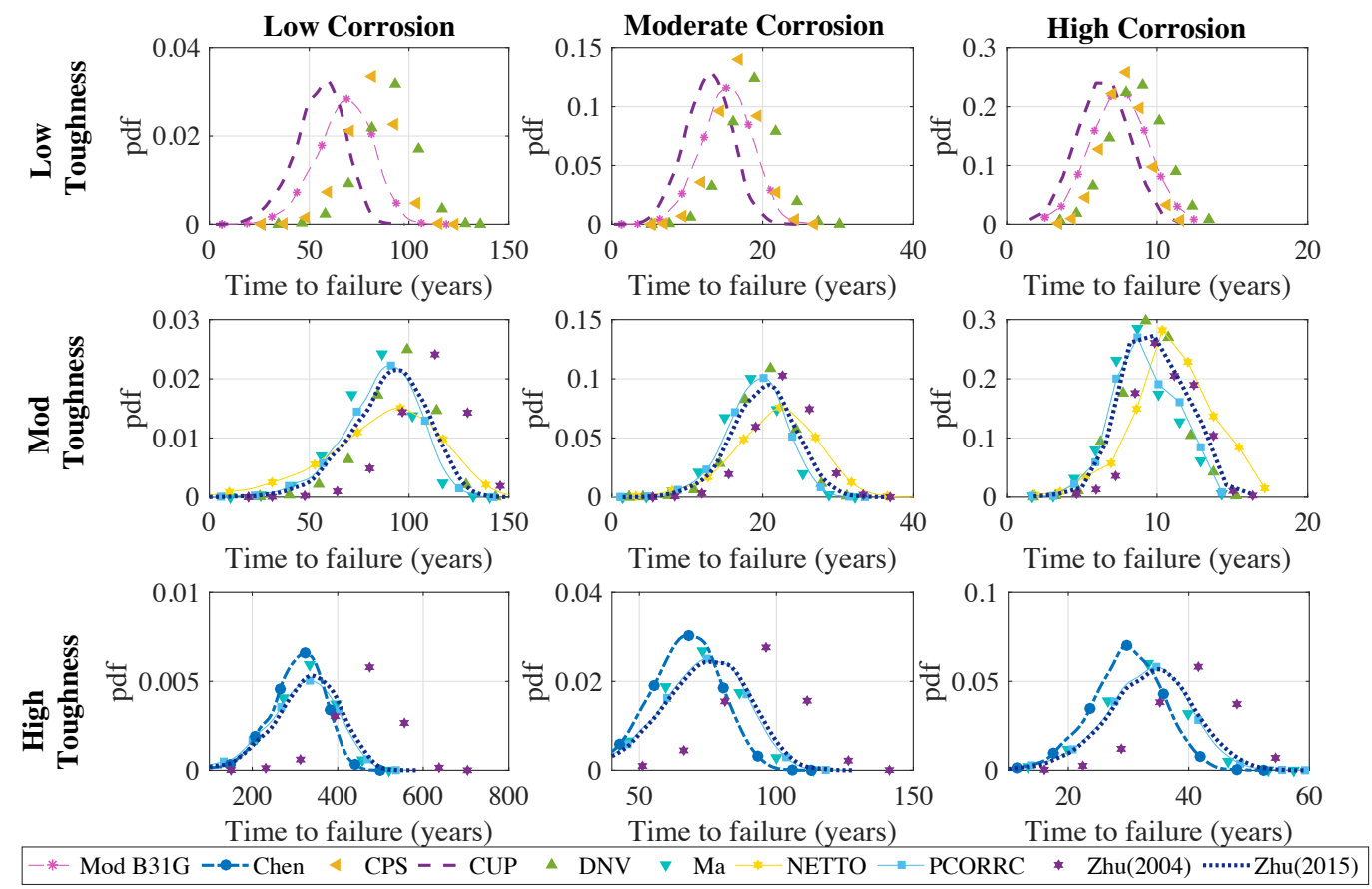

Figure 9: Probability density function of the time to failure per corrosion rate and material toughness

MTTF are expected for any pipe toughness and corrosion rate. For illustrative purposes, this work evaluates the MTTF based on a combined degradation of uniform and localized corrosion that can be gathered with an In-Line inspection; certainly, these results show that there are significantly different predictions that require further analysis.

\subsection{Prediction error comparison}

Some approaches evaluated the prediction accuracy of several models based on experimental (machine-made) and real corrosion defects to evaluate their relevance. One interesting approach in this direction was proposed by Zhou \& Huang [19] based on 150 data points from isolated real corrosion defects in thin-wall pipelines. They compared eight burst capacity models: ASME B31G, B31G Mod, CPS, CSA Z662, DNV RP F-101, PCORRC, RSTRENG, and SHELL92. Based on some observations with test-to-predicted failure bursts, they decided to avoid experimental data for preventing the model error rises significantly and to separate the models from a defect-length threshold. The results obtained suggest that these eight models increase their level of conservatism as the length of the defect rises, but generally the RSTRENG had the best performance. Additionally, this work supports that ASME B31G criterion is severely conservative, but with ModB31G they have some remarkable accurate results for $L_{n}=l / \sqrt{D t} \leq 1.5$ where the predictions are similar to approaches that consider a metal loss profile like RSTRENG and CSA Z662. Based on the mean and COV of the test-to-predicted ratios, they established that the DNV and SHELL approaches are more conservative than the models from CPS and PCORRC, where the latter presents the closer predictions for models that use a maximum-based corrosion depth. Another similar approach was presented by Chauhan et al. [18] based on the models of ASME B31G, B31GMod, RSTRENG, PCORRC, DNV (LPC) model, and SHELL92. To this purpose, they considered 313 burst tests of corrosion defects (both machine-made and real). The conclusions of this report indicate that the machined defects presented less variability than real defects and that the RSTRENG criterion was the most accurate. Cronin [17] obtained similar results based on 40 burst tests once a comparison of ASME B31G, RSTRENG, PCORRC, SHELL92, and CPS was developed.

There are other pieces of work focused on FEM comparisons. For instance, Xu \& Cheng [22] compared three industry pressure standards (ASME B31G, ModB31G, and DNV) based on finite element modeling for high-toughness pipelines. They considered three metal grades (X65, X80, and X100), elliptical shape defects and fixed width and length. Their results illustrate that i) the failure pressure increases for higher metal grades, and ii) the relative error 
Table 9: Mean time to failure for each model considering the material toughness and corrosion rate

\begin{tabular}{|c|c|c|c|c|c|c|c|c|c|}
\hline & \multicolumn{3}{|c|}{ Low Toughness } & \multicolumn{3}{|c|}{ Moderate Toughness } & \multicolumn{3}{|c|}{ High Toughness } \\
\hline \multirow{2}{*}{ Model } & Low & Mod & High & Low & Mod & High & Low & Mod & High \\
\hline & Corr & Corr & Corr & Corr & Corr & Corr & Corr & Corr & Corr \\
\hline ASMEB31G & 54.0 & 13.9 & 6.7 & 71.8 & 18.2 & 8.9 & 224.0 & 63.2 & 30.8 \\
\hline Chen & 74.4 & 15.6 & 7.0 & 76.0 & 16.7 & 7.6 & 304.7 & 66.5 & 29.9 \\
\hline Choi & 65.4 & 14.9 & 6.9 & 41.5 & 13.2 & 6.7 & 67.3 & 32.6 & 19.1 \\
\hline CPS & 80.7 & 16.7 & 7.4 & 83.2 & 17.6 & 7.9 & 357.9 & 74.6 & 32.8 \\
\hline CSA & 55.9 & 12.5 & 5.8 & 52.8 & 12.8 & 6.1 & 155.6 & 42.1 & 20.3 \\
\hline CUP & 54.6 & 12.6 & 6.0 & 40.5 & 10.7 & 5.2 & 139.3 & 37.7 & 18.5 \\
\hline DNV & 90.1 & 18.5 & 8.2 & 95.6 & 20.1 & 9.0 & 381.9 & 81.7 & 36.4 \\
\hline FFS & 49.5 & 11.5 & 5.5 & 47.2 & 11.8 & 5.7 & 169 & 43.9 & 21.0 \\
\hline $\mathrm{Ma}$ & 77.7 & 16.5 & 7.5 & 82.2 & 18.3 & 8.3 & 318.6 & 70.7 & 32.1 \\
\hline ModB31G & 67.6 & 15.2 & 7.1 & 76.8 & 17.5 & 8.2 & 247.2 & 60.7 & 28.5 \\
\hline Netto & 63.5 & 15.4 & 7.3 & 87.9 & 21.6 & 10.1 & 272.7 & 75.6 & 36.0 \\
\hline PCORRC & 83.8 & 17.4 & 7.8 & 86.3 & 19.1 & 8.7 & 313 & 72.3 & 33.0 \\
\hline Phan 1 & 35.5 & 9.7 & 4.8 & 49.4 & 13.6 & 6.8 & 141.3 & 42.2 & 21.2 \\
\hline Phan 2 & 40.5 & 9.8 & 4.7 & 58.4 & 13.7 & 6.4 & 196.3 & 48.7 & 22.7 \\
\hline Phan 3 & 33.3 & 8.7 & 4.4 & 38.8 & 10.3 & 5.1 & 135.8 & 37.7 & 18.6 \\
\hline RAM & 35.1 & 8.4 & 4.1 & 29.4 & 7.7 & 3.8 & 95.8 & 25.3 & 12.4 \\
\hline RPA & 67.6 & 15.1 & 7.0 & 76.8 & 17.5 & 8.2 & 247.2 & 60.7 & 28.5 \\
\hline SHELL & 51.9 & 11.9 & 5.6 & 44.1 & 11.3 & 5.5 & 128 & 36.9 & 18.1 \\
\hline Wang & 35.8 & 9.8 & 4.9 & 47.8 & 12.9 & 6.3 & 142.6 & 40.5 & 20.0 \\
\hline Yeom & 55.8 & 12.5 & 5.8 & 47.6 & 12.3 & 6.0 & 132.8 & 39.8 & 19.7 \\
\hline Zhu (2004) & 94.4 & 19.0 & 8.4 & 110.7 & 22.7 & 10.0 & 425.5 & 93.9 & 41.0 \\
\hline Zhu (2015) & 81.2 & 17.3 & 7.8 & 90.0 & 20.0 & 9.1 & 325.5 & 73.7 & 33.7 \\
\hline Min & 33.3 & 8.4 & 4.1 & 29.4 & 7.7 & 3.8 & 67.3 & 25.3 & 12.4 \\
\hline Mean & 61.3 & 13.8 & 6.4 & 65.2 & 15.4 & 7.2 & 223.7 & 55.5 & 26.1 \\
\hline Max & 94.4 & 19.0 & 8.4 & 110.7 & 22.7 & 10.1 & 425.5 & 93.9 & 41.0 \\
\hline
\end{tabular}

with the FEM simulation increases as defect depth growths, obtaining closer matching for the DNV approach. Terán et al. [23] compared the ASME B31G, RSTRENG, SHELL92, DNV, PCORRC, Fitnet FFS, Choi's model and CPS criteria based on FEM simulations in an API 5L X52 steel pipe with a diameter of $609.6 \mathrm{~mm}$. For this purpose, they implemented the Von Mises criterion in nine simulations with semi-elliptical pits associated with a combined metal loss: uniform (50\%) and localized (50\%) corrosion defects. The results of this comparison indicated that the SHELL92, Fitnet FFS, and ASME B31G are the most conservative approaches, whereas the RSTRENG, PCORRC, and DNV are more accurate. There are other relevant approaches that were already discussed such as Choi et al. [51], Ma et al. [81], and Netto et al. [16]. Other comparisons using FEM are summarized in [23].

To corroborate the aforementioned results and to evaluate the remaining approaches, a final comparison was proposed based on a set of 102 burst tests from experimental tests and 351 FEM simulations; available as a supplementary material of this paper. This dataset was gathered from academic literature to evaluate the ratio of the predicted-to-test burst pressure including 14 intact pipes and 19 records of deeper defects (i.e., $d / t>0.8$ ). The summary of the obtained dataset is shown in Table 10. Table 11 presents the results obtained by each dataset and toughness categories. These results correspond to the ratio between the predicted burst pressure from each model to the reported in the literature.

Table 11 shows that approaches like ModB31G, DNV, Ma, Netto, PCORRC, Chen, and Zhu predict the experimental dataset adequately, whereas ModB31G, Choi, Chen, DNV, Netto, PCORRC, and Yeom are highlighted for the FEM dataset. In both cases, models such as Wang, RAM, and Phan have the lowest accurate predictions. Specifically, from the models selected for low toughness pipes, CPS and DNV approaches have interesting predictions, while CUP and ModB31G underestimate the burst pressure in a greater proportion. The latter could be attributed to the 68 short defects and the 9 intact pipelines considering that the CUP model establishes a relative short unacceptable defect depth for short defects, as shown in Fig. 7 for $l^{2} / D t<20$. For this dataset, other interesting predictions were obtained with the models of Zhu and PCORRC, whereas the worst predictions were associated with the models of FFS, Wang, RAM, SHELL, and Phan. For moderate and high toughness tests, approaches like Ma, Netto, Chen, PCORRC report accurate predictions in both cases, which is somehow expected due to the previous results of PCORRC, Ma, and Netto. Chen is initially limited for high toughness pipes but could be a viable alternative also for moderate toughness pipes. There are other interesting prediction results from DNV, Zhu, and CPS (for moderate toughness); and Choi, 
Table 10: Summary of recollected burst tests

\begin{tabular}{|c|c|c|c|c|c|c|c|c|c|}
\hline$\overline{\text { Ref. }}$ & Data $D[\mathrm{~mm}]$ & $t[\mathrm{~mm}]$ & $\sigma_{y}[\mathrm{MPa}]^{* *}$ & $\sigma_{u}[\mathrm{MPa}]^{* *}$ & $d[\mathrm{~mm}]$ & $l[\mathrm{~mm}]$ & $w[\mathrm{~mm}]^{*}$ & Records & Material \\
\hline [48] & FEM 324 & $3.18-9.73$ & 422.5 & 589.6 & $0.95-3.33$ & $255.6-527.8$ & 95.3 & 10 & X60 \\
\hline [92] & EXP 324 & $9.66-9.91$ & 452 & 542 & $6.76-7.31$ & $255.6-527.8$ & 95.3 & 9 & X60 \\
\hline [17] & EXP 273-864 & $4.57-9.63$ & $350.61-462.3$ & $453.8-587.3$ & $0.00-4.62$ & $0-1432.6$ & - & 39 & X42,X46, X52, X55 \\
\hline [93] & FEM 457-508 & $6.10-19$ & $350-414$ & $547-570$ & $1.83-7.86$ & 5000 & 95.3 & 4 & $\mathrm{X} 46, \mathrm{X} 60$ \\
\hline [93] & EXP 324-508 & $6.35-14.80$ & $285-590$ & $428-689$ & $0.00-10.35$ & $0-5000$ & 95.3 & 17 & X46, X60, X80 \\
\hline [81] & FEM 1016-1219 & $14.6-22$ & $508-524$ & $667-701$ & $2.92-8.76$ & $25-2000$ & - & 195 & $\mathrm{X} 70, \mathrm{X} 80$ \\
\hline [81] & EXP 273-1320 & $2.73-22.9$ & $264-689.5$ & $392-886$ & $1.54-15.41$ & 39.6-1109.9 & - & 23 & X42, X46, X60, X80, X100 \\
\hline [16] & EXP $42-42$ & $2.73-2.76$ & 264 & 392 & $0.00-2.24$ & $0-42$ & $0-13$ & 7 & AISI1020 Mild \\
\hline [94] & EXP 762 & 17.50 & 464.50 & 563.8 & $4.38-13.13$ & $100-300$ & $50-200$ & 7 & X65 \\
\hline [75] & FEM 324-914 & $9.74-25.40$ & $414-465$ & $542-600$ & $0.00-12.25$ & $0-528$ & - & 24 & X60, X65 \\
\hline [59] & FEM 305-508 & $6.01-10.30$ & $317.2-413.7$ & $463-672.5$ & $1.32-7.08$ & $19.35-1016$ & $19.0-679.8$ & 39 & $\mathrm{X} 46, \mathrm{X} 52, \mathrm{X} 60$ \\
\hline [23] & FEM 610 & $9.53-19.05$ & 410 & 528 & 7.16-14.30 & $152.4-609.6$ & - & 9 & $\mathrm{X} 52$ \\
\hline$[67]$ & FEM 102-2286 & $3.40-12.70$ & 262 & 393 & $1.70-10.80$ & $18.4-480.1$ & $14.3-365.8$ & 16 & AISI1020 Mild \\
\hline [22] & FEM 813 & 19.10 & $456-802$ & $570-891$ & $3.82-15.28$ & 200 & - & 12 & X65, X80, X100 \\
\hline [73] & FEM 762 & 15.90 & 532.2 & 626.8 & $3.98-13.91$ & $50-900$ & 50 & 42 & $\mathrm{X} 70$ \\
\hline
\end{tabular}

*Calculated as the $10 \%$ of half circumference, i.e. $0.1 \pi r$. **Completed based on standard material properties.

CSA, ASME, ModB31G, and RPA (for high toughness). These results are anticipated, except for the accurate results from ASME, and its modifications. However, this can be linked to a majority of short defects and their adequate performances therein. Finally, it should be mentioned that the models have similar prediction capabilities for deeper defects (i.e., $d / t>0.8$ ), and only the approaches of CSA, CUP, FFS, RAM, SHELL, and Yeom indicate poor predictions with a mean ratio near to 0.5 . The closer predictions were obtained with the model of Netto, Phan(1), Chen, ASME, Ma, and Wang. Therefore, these approaches could be considered.

Table 11: Predicted-to-test ratio results for each model

\begin{tabular}{|c|c|c|c|c|c|c|c|c|c|c|c|c|}
\hline \multirow[t]{2}{*}{ Dataset } & \multicolumn{2}{|c|}{ Experimental } & \multicolumn{2}{|c|}{ FEM } & \multicolumn{2}{|c|}{ Total } & \multicolumn{2}{|c|}{ Low Tough* } & \multicolumn{2}{|c|}{ Mod Toug* } & \multicolumn{2}{|c|}{ High Toug* } \\
\hline & $\mu$ & $\mathrm{COV}$ & $\mu$ & $\mathrm{COV}$ & $\mu$ & $\mathrm{COV}$ & $\mu$ & $\mathrm{COV}$ & $\mu$ & $\mathrm{COV}$ & $\mu$ & $\mathrm{COV}$ \\
\hline ASME & 0.73 & 0.20 & 0.87 & 0.19 & 0.84 & 0.21 & 0.73 & 0.23 & 0.75 & 0.19 & 0.91 & 0.16 \\
\hline ModB31G & 0.86 & 0.19 & 0.93 & 0.16 & 0.91 & 0.17 & 0.76 & 0.19 & 0.94 & 0.16 & 0.95 & 0.13 \\
\hline RPA & 0.76 & 0.17 & 0.88 & 0.16 & 0.85 & 0.17 & 0.74 & 0.22 & 0.78 & 0.15 & 0.92 & 0.12 \\
\hline CPS & 0.91 & 0.18 & 1.09 & 0.18 & 1.05 & 0.20 & 0.86 & 0.29 & 1.00 & 0.15 & 1.13 & 0.14 \\
\hline Choi & 0.71 & 0.51 & 0.90 & 0.24 & 0.89 & 0.18 & 0.76 & 0.24 & 0.85 & 0.16 & 0.94 & 0.13 \\
\hline CSA & 0.75 & 0.18 & 0.89 & 0.18 & 0.85 & 0.19 & 0.71 & 0.28 & 0.80 & 0.14 & 0.93 & 0.14 \\
\hline CUP & 0.79 & 0.22 & 0.85 & 0.23 & 0.84 & 0.23 & 0.70 & 0.31 & 0.86 & 0.19 & 0.88 & 0.20 \\
\hline DNV & 0.89 & 0.16 & 1.04 & 0.16 & 1.01 & 0.17 & 0.86 & 0.26 & 0.96 & 0.12 & 1.08 & 0.12 \\
\hline FFS & 0.74 & 0.19 & 0.89 & 0.19 & 0.86 & 0.20 & 0.69 & 0.29 & 0.80 & 0.13 & 0.94 & 0.14 \\
\hline $\mathrm{Ma}$ & 0.89 & 0.16 & 1.04 & 0.15 & 1.00 & 0.16 & 0.87 & 0.22 & 0.95 & 0.12 & 1.07 & 0.12 \\
\hline Netto & 0.80 & 0.26 & 0.94 & 0.18 & 0.91 & 0.19 & 0.73 & 0.22 & 0.91 & 0.15 & 0.97 & 0.15 \\
\hline Wang & 0.69 & 0.27 & 0.82 & 0.18 & 0.79 & 0.20 & 0.63 & 0.26 & 0.76 & 0.16 & 0.86 & 0.13 \\
\hline PCORRC & 0.86 & 0.16 & 1.02 & 0.16 & 0.98 & 0.17 & 0.85 & 0.24 & 0.92 & 0.13 & 1.05 & 0.13 \\
\hline RAM & 0.64 & 0.35 & 0.71 & 0.30 & 0.70 & 0.31 & 0.58 & 0.48 & 0.68 & 0.26 & 0.75 & 0.26 \\
\hline SHELL & 0.73 & 0.18 & 0.86 & 0.19 & 0.83 & 0.20 & 0.69 & 0.29 & 0.78 & 0.14 & 0.90 & 0.14 \\
\hline Chen & 0.83 & 0.23 & 1.02 & 0.16 & 0.98 & 0.19 & 0.82 & 0.28 & 0.90 & 0.17 & 1.07 & 0.12 \\
\hline Phan1 & 0.68 & 0.29 & 0.82 & 0.18 & 0.79 & 0.20 & 0.63 & 0.27 & 0.76 & 0.17 & 0.86 & 0.13 \\
\hline Phan2 & 0.72 & 0.18 & 0.84 & 0.17 & 0.81 & 0.18 & 0.64 & 0.25 & 0.78 & 0.13 & 0.89 & 0.11 \\
\hline Phan3 & 0.67 & 0.20 & 0.79 & 0.19 & 0.76 & 0.20 & 0.61 & 0.28 & 0.70 & 0.19 & 0.84 & 0.12 \\
\hline Yeom & 0.73 & 0.18 & 0.87 & 0.18 & 0.84 & 0.19 & 0.71 & 0.27 & 0.77 & 0.13 & 0.91 & 0.13 \\
\hline Zhu04 & 0.93 & 0.16 & 1.09 & 0.16 & 1.05 & 0.17 & 0.90 & 0.23 & 0.99 & 0.12 & 1.13 & 0.12 \\
\hline Zhu15 & 0.97 & 0.15 & 1.13 & 0.16 & 1.10 & 0.17 & 0.97 & 0.22 & 1.05 & 0.14 & 1.16 & 0.14 \\
\hline
\end{tabular}

\subsection{Defect shape influence}

As it was shown in Table 4, burst models are developed based on specific defect shapes that can be divided into rectangular, elliptical, and other shapes, which in turn, define an inherent level of conservatism based on the real metal loss. For instance, burst models using rectangular shapes may underestimate the corroded area in a higher proportion 
than elliptical defects, commonly reported in pitting generation, which can be evidenced in the mean prediction errors in Table 12. In this table, the mean predicted-to-test ratios for the models using elliptical shapes are more accurate, followed by the mixed approaches, and finally by those using a rectangular idealization. This pattern was also recently pointed out by Mokhtari \& Melchers [95] comparing the prediction results of FEM simulations using semi-elliptical and rectangular defect shapes of complex pits. According to the authors, a mean error of 5 and $10.9 \%$ were obtained for these predictions, respectively, for complex defects composed of agglomerated pits following hemispherical shapes [95]. In addition, burst models based on experimental or FEM regressions from a particular defect shape are subjected to uncertain predictions depending on how different is the real defect from the idealization.

Table 12: Mean predicted-to-test ratio depending on the defect idealization

\begin{tabular}{lccc}
\hline Defect idealization & Low Tough & Mod Tough & High Tough \\
\hline Rectangular & 0.73 & 0.82 & 0.94 \\
Elliptical & 0.81 & 0.91 & 1.02 \\
Mixed/other & 0.74 & 0.85 & 0.94 \\
\hline
\end{tabular}

In either case, calibration approaches should be proposed to reduce the bias from the defect shape and the corresponding metal loss descriptors (i.e., depth, length, and width), and to identify the best measurement from on-site inspections (e.g., mean depth, maximum depth) to consider as the parameter in the model. In this direction, Mokhtari $\&$ Melchers recommended an equivalent defect depth that depends on the metal descriptors and the metal loss volume as follows [95]:

$$
d_{e q}=\frac{1}{2}\left(\frac{V}{l w}+d_{\max }\right)
$$

where $d_{\max }$ is the maximum depth, $l$ is the length, and $w$ is the width of the pit. $V$ is the volume of the pit that can be estimated using ultrasonic nondestructive tools based on image acquisition information [96]. The equivalent depth was used in the DNV and PCORRC burst models by these authors obtaining remarkable accurate results in comparison to their initial versions. Unfortunately, volume and area not always reported in ILI inspections but only the mean and the maximum depth, so other calibration approaches should be considered.

\section{Conclusions}

This paper reviewed available approaches to evaluate the reliability of corroded pipelines associated with plastic deformation and a plastic collapse. After a thorough review in academic literature and recognized standards, 22 models that predict the burst pressure of a corroded pipeline were compared based on their level of conservatism. This level was evaluated using the failure criteria, acceptable defect dimensions, failure probability, time to failure, and error prediction. In addition, a comparison based on three level of corrosion rates and three material toughness is also included. The results indicate that for low toughness approaches like DNV, CPS, ModB31G, and CUP could be interesting alternatives; for moderate toughness the models of Ma, PCORRC, Netto, and Zhu have the best predictions; and finally, for high toughness the approaches of Chen, PCORRC, Ma, and Choi have overall remarkable results.

The selection of an adequate burst prediction model can be used to differentiate between a possible leak, burst, and rupture of a pipeline. This distinction is relevant because of their corresponding impact on the surrounding people and environment during pipeline risk assessments. According to some authors like Zhou et al. [97] and CSA Z662 [3], these three events would depend on a combination of three limit state functions: for a leak $\left(g_{1}=0.8 t-d_{\text {max }}\right)$, a burst $\left(g_{2}=P_{b}-P\right)$, and a rupture $\left(g_{3}=P_{r p}-P\right)$. The first function may not indicate a real leak, but a limit state for a serious integrity loss that is not allowed in the Oil \& Gas industry [88], whereas the rupture pressure (i.e., $\left.P_{r p}\right)$ is a resistance of a flawed pipe due to a burst at a corrosion defect [97]. Conservative burst criteria could represent unnecessary interventions that represent a significant economic loss.

The reader should bear in mind that failure probability and mean time to failure results are subject to new information from pipeline inspections, replacements or repairs. This paper implemented the SwRI degradation model and a combined approach based on uniform and localized corrosion defects for illustrative purposes; nevertheless, general time-dependent degradation processes can be used to predict the defect depth $d(t)$, length $l(t)$, and width $w(t)$. In either case, burst predictions can be updated based upon new information by calibrating the model parameters like the metal 


\section{Nomenclature \& Acronyms}

$\alpha \quad$ Thermal Expansion Coefficient

$\alpha_{L C} \quad$ Ratio of localized corrosion defects

$\Delta \theta \quad$ Temperature Variation

$\epsilon_{u} \quad$ Uniform strain at the ultimate strength

$\epsilon_{c r i t} \quad$ Real tension of the pipe

$\gamma, \gamma_{f} \quad$ Soil and fluid unit weights

$\gamma_{m}, \gamma_{d}, \epsilon_{d}$ DNV factors of modeling prediction, defect depth, and fractile value

$\gamma_{L C} \quad$ Length-to-depth ratio of localized defects

$X \quad$ Longitudinal curvature

$\mu \quad$ Poisson ratio

$\sigma_{c}, \sigma_{l} \quad$ Circumferential and longitudinal stresses

$\sigma_{h} \quad$ Hoop Stress

$\sigma_{u} \quad$ Ultimate Strength

$\sigma_{y} \quad$ Yield Strength

$\sigma_{\text {crit }} \quad$ Real stress of the pipe

$\sigma_{\text {equiv }} \quad$ Von Mises Stress

$\sigma_{\text {flow }} \quad$ Flow stress

$\sigma_{P c}, \sigma_{P l}$ Circumferential and longitudinal stresses due to inner pressure

$\sigma_{\text {Resc }}, \sigma_{\text {Resl }}$ Circumferential and longitudinal residual stresses

$\sigma_{S c} \quad$ Circumferential bending stress due to external loads

$\sigma_{S l} \quad$ Longitudinal stress due to thermal expansion

$\sigma_{T c} \quad$ Circumferential bending stress due to traffic loads

$\sigma_{T l} \quad$ Maximum longitudinal bending stress

$a_{d} \quad$ Standard deviation of $d / t$

$A_{o}, A_{c} \quad$ Intact and corroded areas

$B_{d} \quad$ Width of the Ditch

$C_{d} \quad$ Coefficient of earth pressure

$C_{t} \quad$ Surface Load Coefficient

$D \quad$ Pipeline Diameter

$d, d_{a}, d_{c}$ Defect, average, and critical depths

$d_{T}, l_{T} \quad$ Defect depth and length at time $T$

E Elasticity modulus

$e_{i} \quad$ CSA model errors

$F \quad$ Surface Wheel Load

$g^{f} \quad$ Geometric factor

$g_{i} \quad$ Limit state function

$I_{c} \quad$ Impact factor

$k_{d} \quad$ Deflection coefficient

$k_{m} \quad$ Bending Coefficient

$k_{U C}, n_{c} \quad$ Uniform corrosion parameters

$l \quad$ Defect length

$L_{e} \quad$ Effective Pipe Length
$M \quad$ Folias Factor

$n \quad$ Strain hardening exponent

$n_{R}, \sigma_{R} \quad$ Ramberg-Osborg parameters

$P \quad$ Operating Pressure

$P_{f} \quad$ Probability of failure

$P_{o} \quad$ External pressure

$P_{b}, P_{b i} \quad$ Burst Pressure for corroded and intact pipes

$P_{L G} \quad$ Burst Pressure for a pipe with an axial crack with infinite extension

$P_{p p} \quad$ Burst Pressure for a perfect pipe

$P_{r p} \quad$ Rupture Pressure

$r, r_{i} \quad$ Pipeline outer and inner radius

$s t D[$ ] Standard deviation of a given set

$t \quad$ Pipeline Wall Thickness

$t_{c} \quad$ Corroded layer

$w \quad$ Defect width

ASME American Society of Mechanical Engineers

ASSY Average Shear Stress Yield

COV Coefficient of Variation

CPS Corroded Pipe Strength

CSA Canadian Standard Association

DNV Det Norske Veritas

EXP Experimental test

FEM Finite Element Modeling

FOSM First Order Second Moment

ILI In-Line Inspection

IMP Instituto Mexicano del Petróleo

KAPA Kiefner and Associates Pipe Assessment

LLS Leakage Limit State

LOC Loss of Containment

LPC Linear Pipeline Corrosion Criterion

MFL Magnetic Flux Leakage

MOP Maximum Allowable Pressure

MTTF Mean Time to Failure

PCORRC Pipeline Corrosion Criterion

PEMEX Petróleos Mexicanos

RAM Risk Assessment and Management

RPA Rectangular Parabolic Area

SCC Stress Corrosion Cracking

SCF Stress Concentration Factor

ULS Ultimate Limit State

UT Ultrasonic Technique

loss extent or updating the load (operating pressure) distribution parameters. For this purpose, different approaches can be used like a residual minimization or Meta-models based on Bayesian approaches [98]. 


\section{Acknowledgments}

R. Amaya-Gómez thanks the National Department of Science, Technology and Innovation of Colombia for the PhD scholarship (COLCIENCIAS Grant No. 727, 2015) and Campus France for the Eiffel Excellence Program (2018).

\section{References}

[1] M. Sánchez-Silva and G-A Klutke. Reliability and life-cycle analysis of deteriorating systems. Springer series in Reliability Engineering. Springer, 2016.

[2] B.J. Leira. Optimal Stochastic Control Schemes within a Structural Reliability Framework, chapter Structural Limit States and Reliability Measures, pages 3-12. Springer International Publishing, Cham, 2013.

[3] CSA. CSA Z662-07: Limit state equation for burst of large leaks and rupture for corrosion defect. Technical report, Canadian Standard Association, 2007.

[4] J. Zhang, Z. Liang, and C. Han. Effect of surrounding soil on stressstrain response of buried pipelines under ground loads. The IES Journal Part A: Civil \& Structural Engineering, 8(3):197-203, 2015.

[5] M.J. O'Rourke and X. Liu. Response of Buried Pipelines Subject to Earthquake Effects. MCEER monograph. Multidisciplinary Center for Earthquake Engineering Research, 1999.

[6] D. Fakhravar, N. Khakzad, G. Reniers, and V. Cozzani. Security vulnerability assessment of gas pipelines using Discrete-time Bayesian network. Process Safety and Environmental Protection, 111:714 - 725, 2017.

[7] Pipeline and Hazardous Materials Safety Administration. Pipeline Incident Flagged Files, January 2016.

[8] F. Schoefs, X. Aduriz, O. Bernard, and B. Capra. Comparison of Additional Costs for Several Replacement Strategies of Randomly Ageing Reinforced Concrete Pipes. Computer-Aided Civil and Infrastructure Engineering, 24(7):492-508.

[9] S. Zhang and W. Zhou. Cost-based optimal maintenance decisions for corroding natural gas pipelines based on stochastic degradation models. Engineering Structures, 74:74 - 85, 2014

[10] M. Ahammed and R.E. Melchers. Probabilistic analysis of underground pipelines subject to combined stresses and corrosion. Engineering Structures, 19(12):988 - 994, 1997.

[11] A. Amirat, A. Mohamed-Chateauneuf, and K. Chaoui. Reliability assessment of underground pipelines under the combined effect of active corrosion and residual stress. International Journal of Pressure Vessels and Piping, 83(2):107 - 117, 2006.

[12] M. Orazem. Underground Pipeline Corrosion. Detection, analysis and prevention. Woodhead Publishing series in metals and surface engineering. Elsevier Science, 2014

[13] G.A. Antaki. Piping and Pipeline Engineering: Design, Construction, Maintenance, Integrity, and Repair. Taylor and Francis, 2003.

[14] ASME. ASMEB31G: Manual for determining the remaining strength of corroded pipelines. Technical report, American Society of Mechanical Engineers, 2009.

[15] DNV. DNV-RP-F101: Recommended practice. corroded pipelines. Technical report, Det Norske Veritas, Høvik, Norway, 2010.

[16] T.A. Netto, U.S. Ferraz, and S.F. Estefen. The effect of corrosion defects on the burst pressure of pipelines. Journal of Constructional Steel Research, 61(8):1185 - 1204, 2005. Second Brazilian special issue.

[17] D. Cronin. Assessment of Corrosion Defects in Pipelines. PhD thesis, University of Waterloo, 2000.

[18] V. Chauhan and J. Brister. A review of methods for assessing the remaining strength of corroded pipelines. Technical report, GL Industrial Services UK Ltd, 2009. Report Number 6781.

[19] W. Zhou and G.X. Huang. Model error assessments of burst capacity models for corroded pipelines. International Journal of Pressure Vessels and Piping, 99-100:1 - 8, 2012.

[20] S. Hasan, F. Khan, and S. Kenny. Probability assessment of burst limit state due to internal corrosion. International Journal of Pressure Vessels and Piping, 89:48 - 58, 2012.

[21] B. Keshtegar and M. el Amine Ben Seghier. Modified response surface method basis harmony search to predict the burst pressure of corroded pipelines. Engineering Failure Analysis, 89:177 - 199, 2018.

[22] L.Y. Xu and Y.F. Cheng. Reliability and failure pressure prediction of various grades of pipeline steel in the presence of corrosion defects and pre-strain. International Journal of Pressure Vessels and Piping, 89:75 - 84, 2012.

[23] G. Terán, S. Capula-Colindres, J.C. Velázquez, M.J. Fernández-Cueto, and D. Angeles-Herrera. Failure Pressure Estimations for Pipes with Combined Corrosion Defects on the External Surface: A comparative study. International Journal of Electrochemical Science, 12:10152$10176,2017$.

[24] X-K. Zhu and B.N. Leis. Average shear stress yield criterion and its application to plastic collapse analysis of pipelines. International Journal of Pressure Vessels and Piping, 83(9):663 - 671, 2006.

[25] X.K. Zhu and B.N. Leis. Evaluation of burst pressure prediction models for line pipes. International Journal of Pressure Vessels and Piping, $89: 85-97,2012$

[26] M. Ahammed and R.E. Melchers. Reliability of Underground Pipelines Subject to Corrosion. Journal of Transportation Engineering, 120(6):989-1002, 1994

[27] M.G. Spangler and R.L. Handy. Soil Engineering. Harper \& Row series in civil engineering. Harper \& Row, 1982.

[28] A. Amirat, K. Chaoui, Z. Azari, and G. Pluvinage. Residual stress analysis in seamless APIX60 Steel Gas Pipelines. Revue Sciences et Technologie, de l'Université Mentouri de Constantine, (21B):7 - 14, 2004.

[29] Y. Sahraoui, A. Chateauneuf, and R. Khelif. Inspection and maintenance planning of underground pipelines under the combined effect of active corrosion and residual stress. International Journal of Steel Structures, 17(1):165-174, 2017.

[30] A. Amirat, B. Bounamous, R. Khelif, A. Chateauneuf, and K. Chaoui. Reliability Assessment of Pipelines using Phimeca Software. In Safety, Reliability and Risks Associated with Water, Oil and Gas Pipelines, pages 233-259, Dordrecht, 2008. Springer Netherlands. 
[31] J. Ji, D.J. Robert, C. Zhang, D. Zhang, and J. Kodikara. Probabilistic physical modelling of corroded cast iron pipes for lifetime prediction. Structural Safety, 64:62 - 75, 2017

[32] C.Q. Li and M. Mahmoodian. Risk based service life prediction of underground cast iron pipes subjected to corrosion. Reliability Engineering \& System Safety, 119:102 - 108, 2013.

[33] A. Fahimi, T.S. Evans, J. Farrow, D.A. Jesson, M.J. Mulheron, and P.A. Smith. On the residual strength of aging cast iron trunk mains: Physically-based models for asset failure. Materials Science and Engineering: A, 663:204 - 212, 2016.

[34] A.C. Palmer and King R.A. Design to Resist Internal Pressure, pages 328-335. PennWell, 2008.

[35] M.A. Maes, M. Dann, and M.M. Salama. Influence of grade on the reliability of corroding pipelines. Reliability Engineering \& System Safety, 93(3):447 - 455, 2008. Probabilistic Modelling of Structural Degradation.

[36] X-K Zhu and L. Brian. Analytic prediction of plastic collapse failure pressure of line pipes. In Proceedings of the ASME 2005 Pressure Vessels and Piping Conference, Denver, USA, 2005. PVP2005-71204.

[37] M. Law and G. Bowie. Prediction of failure strain and burst pressure in high yield-to-tensile strength ratio linepipe. International Journal of Pressure Vessels and Piping, 84(8):487 - 492, 2007.

[38] J.F. Kiefner and A.R. Duffy. Summary of Research to Determine the Strength of Corroded Areas in Line Pipe. Technical report, Battelle Columbus Laboratories, 1971.

[39] W.A. Maxey, J.F. Kiefner, R.J. Eiber, and Duffy A.R. Ductile Fracture Initiation, Propagation and Arrest in Cylindrical Vessels, Fracture Toughness. Technical report, 1971. ASTM STP514.

[40] E.S. Folias. The Stresses in a Cylindrical Shell Containing an Axial Crack. Technical report, Aerospace Research Laboratories, Office of Aerospace Research, United States Air Force, 1964. ARL 64-174.

[41] Folias E.S. Predicting Failures in Cylindrical Pressurized Vessels from Tests Carried Out on Flat Plates. In 9th International Conference on Pressure Vessel Technology, Sydney, Australia, 2000.

[42] A.C. Benjamin, J.L.F. Freire, R.D. Vieira, and E.Q. de Andrade. Burst tests on pipeline containing closely spaced corrosion defects. In 25th International Conference on Offshore Mechanics and Artic Engineering, Hamburg, Germany, 2006. OMAE2006-92131.

[43] Z. Mustaffa. Developments in Corrosion Protection. 2014.

[44] A. Cosham and P. Hopkins. The assessment of corrosion in pipelines. Guidance in the pipeline defect assessment manual (PDAM). In Pipeline Pigging and Integrity Management Conference, Amsterdam, The Netherlands, 2004.

[45] A.P. Teixeira, C. Guedes Soares, T.A. Netto, and S.F. Estefen. Reliability of pipelines with corrosion defects. International Journal of Pressure Vessels and Piping, 85(4):228 - 237, 2008.

[46] J.E. Abdalla Filho, R.D. Machado, R.J. Bertin, and M.D. Valentini. On the failure pressure of pipelines containing wall reduction and isolated pit corrosion defects. Computers \& Structures, 132:22 - 33, 2014.

[47] Kiefner and Associates, Inc. KAPA Kiefner \& Associates, Inc. Pipe Assessment-Spreadsheet Documentation. http: //kiefner. com/ wp-content/uploads/2013/05/KAPA.pdf, 2000.

[48] E.Q. Andrade and A.C. Benjamin. Structural Evaluation of Corrosion Defects in Pipelines: Comparison of FE Analyses and Assessment Methods. In Proceedings of the Fourteenth International Offshore and Polar Engineering Conference, pages 120-126, Toulon, France, 2004.

[49] A.C. Benjamin and E.Q. Andrade. Modified method for the assessment of the remaining strength of corroded pipelines. In Rio Pipeline Conference, Rio de Janeiro, Brasil, 2003.

[50] K.F. Tee and K. Pesinis. Reliability prediction for corroding natural gas pipelines. Tunnelling and Underground Space Technology, 65:91 $105,2017$.

[51] J.B. Choi, B.K. Goo, J.C. Kim, Y.J. Kim, and W.S. Kim. Development of limit load solutions for corroded gas pipelines. International Journal of Pressure Vessels and Piping, 80(2):121 - 128, 2003.

[52] Y. Chen, H. Zhang, J. Zhang, X. Li, and J. Zhou. Failure analysis of high strength pipeline with single and multiple corrosions. Materials \& Design, 67:552 - 557, 2015.

[53] D.S. Cronin and R.J. Pick. Prediction of the failure pressure for complex corrosion defects. International Journal of Pressure Vessels and Piping, 79(4):279 - 287, 2002.

[54] N.L. Svensson. The Bursting Pressure of Cylindrical and Spherical Vessels. Journal of Applied Mechanics, 25:89-96, 1958.

[55] ASM International. Representation of Stress-Strain Behavior, pages 1-20. ASM International, 2002.

[56] X-K Zhu and L. Brian. Influence of Yield-to-Tensile Strength Ratio on Failure Assessment of Corroded Pipelines. Journal of Pressure Vessel Technology, 127(4):436-442, 2005.

[57] W. Ramberg and W.R. Osgood. Description of stress-strain curves by three parameters. Technical report, National Advisory Committee for Aeronautics, Washington, USA, 1943. Note No 902.

[58] M. Chebaro and W. Zhou. A Limit State Function for Pipelines Containing Long Corrosion Defects. In 2010 8th International Pipeline Conference, Calgary, Canada, 2010. IPC2010-31324.

[59] Y. Shuai, J. Shuai, and K. Xu. Probabilistic analysis of corroded pipelines based on a new failure pressure model. Engineering Failure Analysis, 81:216 - 233, 2017.

[60] H. Liu, F. Khan, and P. Thodi. Revised burst model for pipeline integrity assessment. Engineering Failure Analysis, 80:24 - $38,2017$.

[61] FITNET fitness-for-service (FFS) procedure, vol.1. Technical report, GKSS Research Centre, Geesthacht, Germany, 2008.

[62] M. Koçsak. FITNET European Fitness for Service Network. Final Technical Report. Technical report, GKSS Research Centre, Geesthacht, Germany, 2006. GTC1 200143049.

[63] G. Qian, M. Niffenegger, and S. Li. Probabilistic analysis of pipelines with corrosion defects by using FITNET FFS procedure. Corrosion Science, 53(3):855-861, 2011.

[64] S. Cicero, R. Lacalle, R. Cicero, and D. Ferreño. Assessment of local thin areas in a marine pipeline by using the FITNET FFS corrosion module. International Journal of Pressure Vessels and Piping, 86(5):329 - 334, 2009.

[65] N. Sakakibara, S. Kyriakides, and E. Corona. Collapse of partially corroded or worn pipe under external pressure. International Journal of Mechanical Sciences, 50(12):1586 - 1597, 2008.

[66] T.A. Netto. A simple procedure for the prediction of the collapse pressure of pipelines with narrow and long corrosion defects Correlation 
with new experimental data. Applied Ocean Research, 32(1):132 - 134, 2010.

[67] N. Wang and M.S. Zarghamee. Evaluating Fitness-for-Service of Corroded Metal Pipelines: Structural Reliability Bases. Journal of Pipeline Systems Engineering and Practice, 5(1):04013012, 2014.

[68] Z. Mustaffa and P. van Gelder. A Review and Probabilistic Analysis of Limit State Functions of Corroded Pipelines. In Proceedings of the 20th International Offshore and Polar Engineering Conference, pages 626-632, Beijing, China, 2010.

[69] B.N. Leis and D.R. Stephens. An Alternative Approach to Assess the Integrity of Corroded Line Pipe - Part I: Current Status. In Proceedings of the 7th International Offshore and Polar Engineering Conference, pages 624-634, Honolulu, 1997.

[70] B.N. Leis and D.R. Stephens. An Alternative Approach to Assess the Integrity of Corroded Line Pipe - Part II: Alternative Criterion. In Proceedings of the 7th International Offshore and Polar Engineering Conference, pages 635-641, Honolulu, 1997.

[71] D.R. Stephens and B.N. Leis. Development of an alternative criterion for residual strength of corrosion defects in moderate-to high-toughness pipe. In 2000 International Pipeline Conference, Alberta, Canada, 2000. IPC2000-192.

[72] Y-p. Kim, W-s. Kim, Y-k. Lee, and K-h. Oh. The evaluation of failure pressure for corrosion defects within girth or seam weld in transmission pipelines. In 2004 International Pipeline Conference, Alberta, Canada, 2004. IPC2004-216.

[73] K.J. Yeom, Y-K Lee, K.H. Oh, and W.S. Kim. Integrity assessment of a corroded API X70 pipe with a single defect by burst pressure analysis. Engineering Failure Analysis, 57:553 - 561, 2015.

[74] K.J. Yeom, W.S. Kim, and K.H. Oh. Integrity assessment of API X70 pipe with corroded girth and seam welds via numerical simulation and burst test experiments. Engineering Failure Analysis, 70:375 - 386, 2016.

[75] H.C. Phan, A.S. Dhar, and B.C. Mondal. Revisiting burst pressure models for corroded pipelines. Canadian Journal of Civil Engineering, 44(7):485-494, 2017.

[76] R.G. Bea. RAM PIPE REQUAL: A Risk Assessment \& Management based process for the Requalification of Marine Pipelines. In Alaskan Arctic Offshore Pipeline Workshop, Anchorage, Alaska, 1999.

[77] R. Bea, R. Iverse, X. Chen, and A. Kareem. RAM PIPE REQUAL Pipeline Requalification Guideline Project. Report 2. Technical report, PEMEX, IMP, and MMS, 1999. MMS Order No. 1435-01-98-PO-15219. PEMEX No. 7TRDIN022798.

[78] R.G. Bea, C. Smith, and V. Valdes. Requalification and Maintenance of Marine Pipeline Infrastructures. Journal of Infrastructure Systems, 6(3):89-96, 2000.

[79] X-K Zhu and L. Brian. Influence of the Yield-to-tensile strength ratio on the failure assessment of corroded pipelines. In Proceedings of the ASME 2003 Pressure Vessels and Piping Conference, pages 23-30, Cleveland, USA, 2004. PVP2003-2004.

[80] X-K Zhu. A new Material Failure Criterion for Numerical Simulation of Burst Pressure of Corrosion Defects in Pipelines. In Proceedings of the ASME 2015 Pressure Vessels and Piping Conference, Boston, USA, 2015. PVP2015-45713.

[81] B. Ma, J. Shuai, D. Liu, and K. Xu. Assessment on failure pressure of high strength pipeline with corrosion defects. Engineering Failure Analysis, 32:209-219, 2013.

[82] B. Keshtegar and M. Miri. Reliability analysis of corroded pipes using conjugate HLRF algorithm based on average shear stress yield criterion. Engineering Failure Analysis, 46:104 - 117, 2014.

[83] M.A. Ghani, G. Tewfik, and D. Djahida. Determination of Limit Load Solution for the Remaining Load-Carrying Capacity of Corroded Pipelines. Journal of Vessels Technology, 138(5), 2015.

[84] F.J. Klever, G. Stewart, and C. Van der Valk. New developments in burst strength predictions for locally corrode pipes. In Offshore Mechanics and Arctic Engineering (OMAE) Conference, Copenhagen, Denmark, 1995.

[85] D. Ritchie and S. Last. Burst criteria of corroded pipelines- defect acceptance criteria. In EPRG/RPC 10th Biennial Joint Technical Meeting on line pipe research, pages 1-11, Cambridge, United Kingdom, 1995. Paper 32.

[86] Zhang Y. M., Tan T. K., Xiao Z. M., Zhang W. G., and Ariffin M. Z. Failure assessment on offshore girth welded pipelines due to corrosion defects. Fatigue \& Fracture of Engineering Materials \& Structures, 39(4):453-466, 2016.

[87] H. Ye and Z. Yan, S. Jin. Collapse of Corroded Pipelines under Combined Tension and External Pressure. PLoS ONE, 11:1-17, 2016.

[88] F. Caleyo, J.L. González, and J.M. Hallen. A study on the reliability assessment methodology for pipelines with active corrosion defects. International Journal of Pressure Vessels and Piping, 79(1):77 - 86, 2002.

[89] A Kale, BH Thacker, N Sridhar, and JC Waldhart. A probabilistic model for internal corrosion of gas pipeline. In 2004 International Pipeline Conference, Alberta, Canada, 2004.

[90] R. Amaya-Gómez, M. Sánchez-Silva, and F. Muñoz. Pattern recognition techniques implementation on data from In-Line Inspection (ILI). Journal of Loss Prevention in the Process Industries, 44:735 - 747, 2016.

[91] Y. Sahraoui, R. Khelif, and A. Chateauneuf. Maintenance planning under imperfect inspections of corroded pipelines. International Journal of Pressure Vessels and Piping, 104:76 - 82, 2013.

[92] A.C. Benjamin, R.D. Vieira, J.L.F. Freire, and J.T.P. de Castro. Burst tests on pipeline with long external corrosion. In 2000 International Pipeline Conference, Alberta, Canada, 2000. IPC2000-193.

[93] J.L.C. Diniz, R.D. Vieira, J.T. Castro, A.C. Benjamin, and J.L.F. Freire. Stress and Strain Analysis of Pipelines with Localized Metal Loss. Experimental Mechanics, 46(6):765-775, 2006.

[94] C-K. Oh, Y-J Kim, J-H Baek, Y-P Kim, and W-S Kim. Ductile failure analysis of API X65 pipes with notch-type defects using a local fracture criterion. International Journal of Pressure Vessels and Piping, 84(8):512 - 525, 2007.

[95] M. Mokhtari and R.E. Melchers. A new approach to assess the remaining strength of corroded steel pipes. Engineering Failure Analysis, 93:144-156, 2018.

[96] H. Ravanbod and A. Jalali. Configurable ultrasonic flaw classification of oil pipelines. Nondestructive Testing and Evaluation, 23(1):43-55, 2008.

[97] W. Zhou, H.P. Hong, and S. Zhang. Impact of dependent stochastic defect growth on system reliability of corroding pipelines. International Journal of Pressure Vessels and Piping, 96 and 97:68 - 77, 2012.

[98] M. Aghagholizadeh and F.N. Catbas. A Review of Model Updating Methods for Civil Infrastructure Systems, pages 83-99. Saxe-Coburg Publications, 2015. 